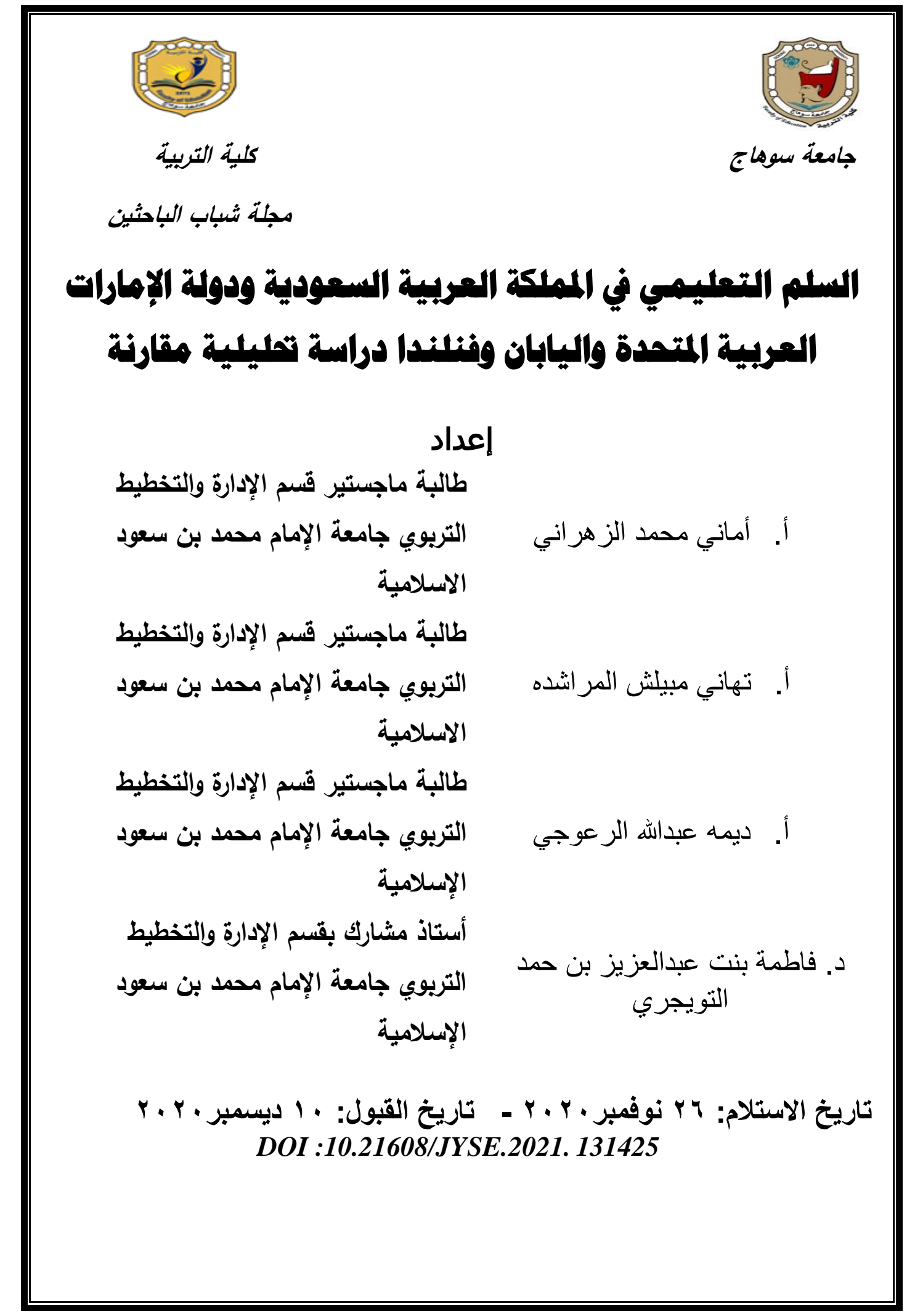


تهدف هذه الدراسة الى معرفة واقع السلم التعليمي في النظام التعليمي بالمملكة العربية السعودية والقوى والعوامل المؤثرة فيه، واستخدمت الباحثات المنهج المقارن، للمقارنة بالسلم التعليمي في فنلندا واليابان والامارات العربية المتحدة وإيجاد أوجه الثبه والاختلاف لوضع وإنع تصور عام لكيفية الاستفادة في تطوير السلم التعليمي السعودي في ضوء خبرات الدول المقارنة وإعادة النظر في المرحلة الثانوية ومرحلة رياض الأطفال، وتوصلت الباحثات الى الى

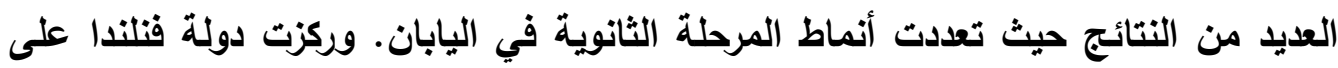
مرحلة ما قبل الابتائي بشكل كبير وعلى الجانب المهني ما بعد المرحلة المتوسطة، وتفردت دولة الإمارات العربية المتحدة بسلم تعليمي مختلف، واستحداثها لمسارات جديدة للتعليم الثانوي. وأوصت الاراسة بأهمية إجراء الدراسات والبحوث وعقد المؤتمرات حول تطوير السلم التعليمي في المملكة العربية السعودية. كلمات مفتاحية: (السلم التعليمي، التعليم الإلزامي، مراحل التعليم، فنلندا، اليابان)

\section{Summary of research:}

This study aims to know the reality of the educational ladder in the educational system in Saudi Arabia and the forces and factors affecting it, and the researchers used the comparative method, to compare the educational ladder in Finland, Japan and The United Arab Emirates to find similarities and differences to develop a general perception of how to benefit the development of the Saudi educational ladder in light of the experiences of comparative countries and the review of secondary and kindergarten levels, and the researchers reached many recommendations, most notably, conducting studies and research and holding conferences on the development of educational ladder in Saudi Arabia. 
يواجه العالم في القرن الحادي والعشرون العديد من التحديات وفي كافة المجالات، ويعد التسارع و التطور في عالم المعلومات والتكنولوجيا من ابرز تلك التحديات، ولأن التعليم من ابرز المجالات الحيوية في بناء الفرد والمجتمع فان النظام التعليمي يصبح مصدرا للإلهام والإبداع والإنتاج إذا ما تتاغم وتكامل مع الأنظمة السياسية والاتئصادية والاجتماعية السائدة لمواجهة تلك التحديات، ولذا تلجأ غالبية الدول بعد كل نكبة أو الكسار إلى النظر بعناية لنظامها التعليمي، ودوره في إيجاد أنسب الوسائل وأنجح البدائل للخروج من الأزمات. (بدران،

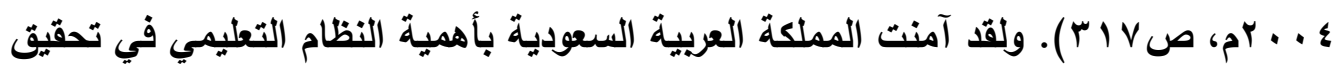
التنمية الثاملة في كآفة المجالات، ويأن العنصر البشري هو الأساس في ذلك؛ لذا أولته

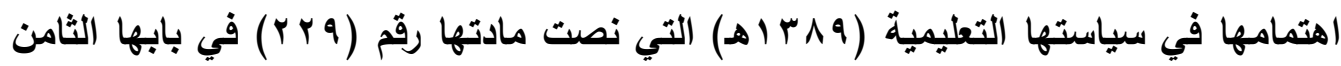
على أن الدولة تعد الطاقة البشرية هي المنطلق في استثمار سائر طاقاتها، وأن العناية بهذه

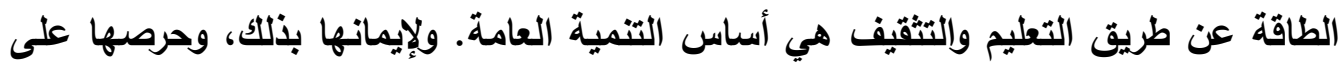
تحقيقه، فقد نصت المادة رقم (r YrT) في وثيقة سياسة التعليم على أن التعليم مجاني في كافة أنواعه ومراحله. (البابطين، 9 1 • rم) ويعد السلم التعليمي، من المعايير المهمة التي يُعول عليها في الارتقاء بجودة التعليم، وهو يختلف من بلد لآخر، وفقتًا لمرئيات خبراء التربية في كل بلا، وإذا كانت بعض الدول قد اعتمدت سلما تعليميا بعينه واستقرت عليه دون

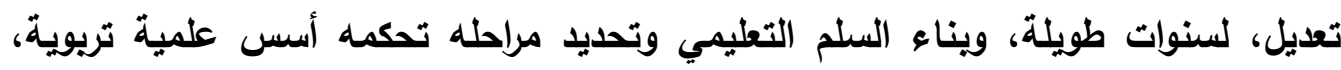
وسيكولوجية ترتبط بخصائص النمو ومتطلبات النضج العقلي والنفسي، ويناءً عليها يتم تنمية الاستعداد واكساب المعارف والمهارات، مما ينعكس مردوده على العملية التعليمية إذ انه

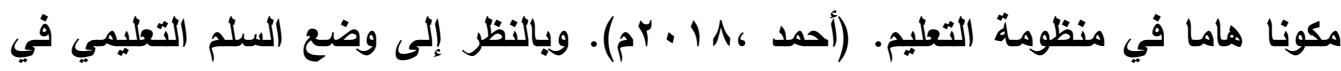

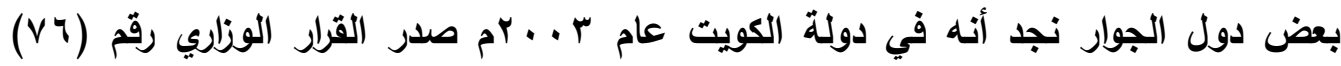
بثأن تعديل السلم التعليمي والذي أصبح خمس سنوات للمرحلة الابتدائية وأربعة سنوات

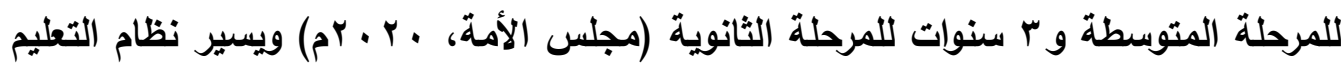
العام في سلطنة عمان على أساس ثلاثة مراحل، مرحلة التعليم قبل المدرسي التي توليه

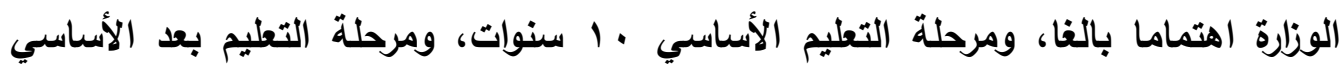

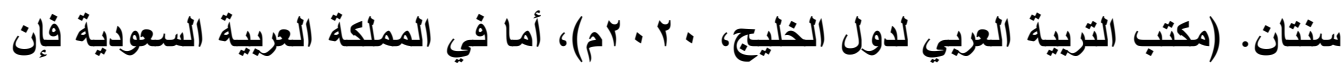


السلم التعليمي كتقسيم للمراحل لم يطرأ عليه أي تغيير منذ انشاء مديرية المعارف عام

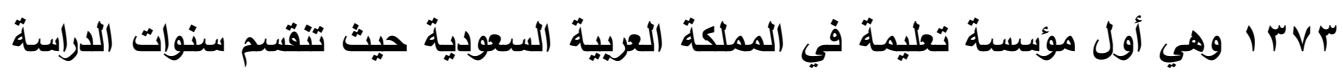

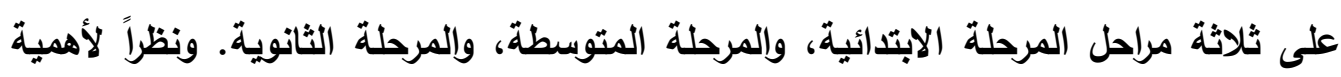
الاطلاع على تجارب الدول المختلفة من خلال الدراسات التربوية المقارنة والتي تبرز أهميتها في إضافة ابعاد جليده في ضوء الخبرات والتجارب الإصلاحية للنظم التعليمية المختلفة، وليساير السلم التعليمي السعودي التطوير تم الوقوف على تجارب رائدة في اصلاح وتطوير

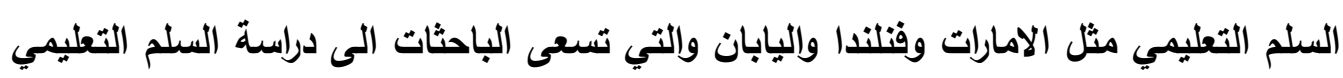
فيها وإمكانية الاستفادة من ذلك لتطوير السلم التعليمي والذي عانى الجمود على مر السنوات الماضية. مشكلة الدر اسة: مئة ان السُلَمَ التعليمي في جوهره، استراتيجية للتخطيط عالية الأهمية لتنظيم سنوات الدراسة،

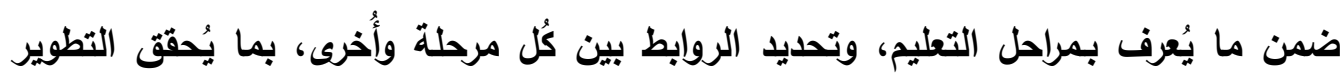

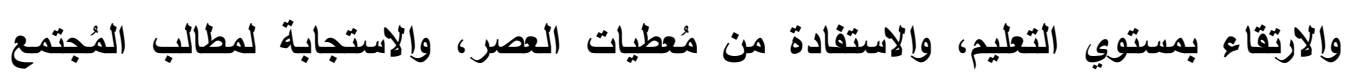
وحاجات التنمية، وليس هناك من سلم تعليمي مثالي، بحيث يُمكن تطبيقه في كُل البيئات،

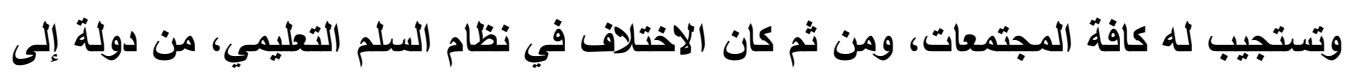

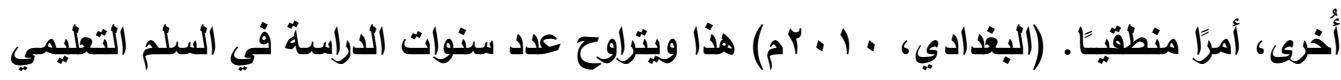

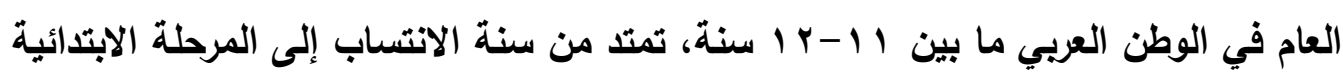

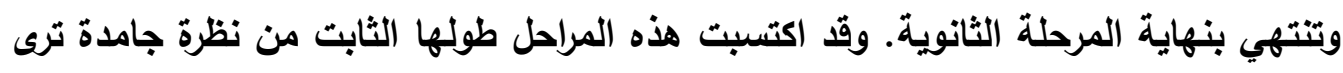
أن المعرفة ثابتة وأن تحصيلها يقاس بالسنوات والمراحل، وأن المدرسة هي المؤسسة الوحيدة

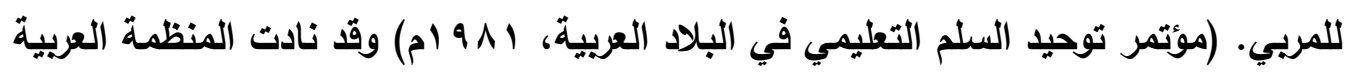

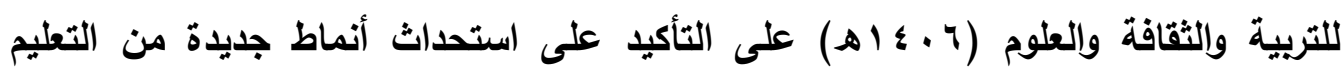

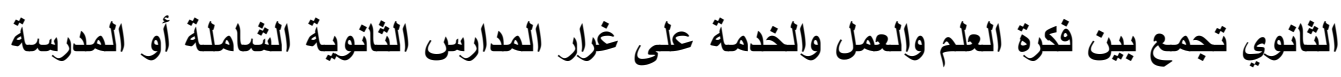
الثانوية الفنية لإمكان إزالة الفوارق في توجيه الطلبة بين فرعي الدراسة العلمي والأدبي.

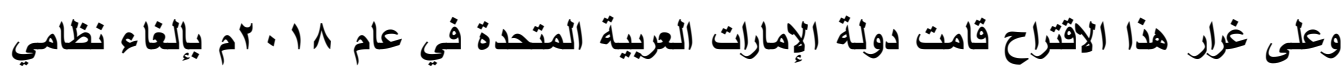
العلمي والادبي واستحداث مساري العام والمتقدم، لمواكبة خططها المستقبلية في التقدم العلمي التي كان من أثارها انتهاج سلم تعليمي جليد في نظامها التعليمي. (البوابة الرسمية 


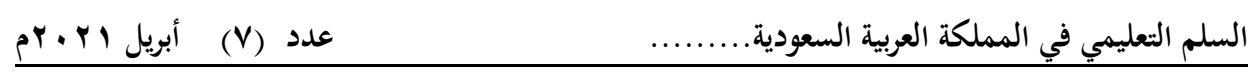

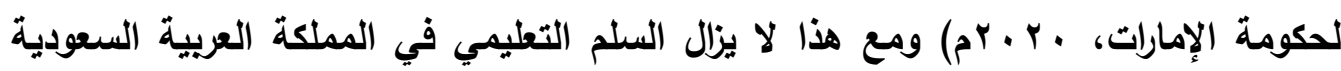

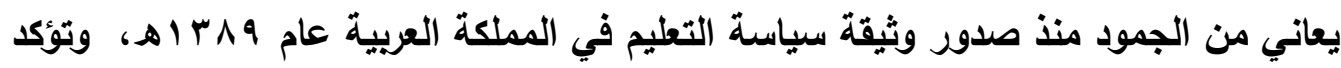

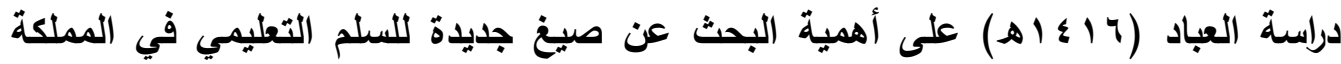
العربية السعودية في الشكل أو في المحتوى أو في كليهما من أجل إعادة توجيه مسار التعليم، فجاء التركيز على مرحلة التعليم الثانوي الذي يذكر أنها بعيدة كل البعد عما هو

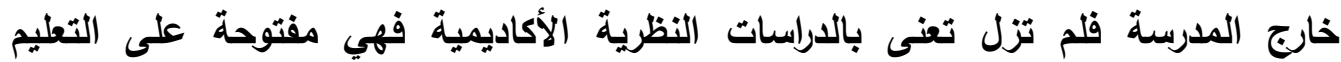
الجامعي، مغلقة عن سوق العمل والدراسات المهنية والحرفية، ويشير أيضا إلى أن مرحلة رياض الأطفال مرحلة ذات أهمية بالغة في تكوين الجانب التعليمي وإلنفسي للأطفال، فعملية

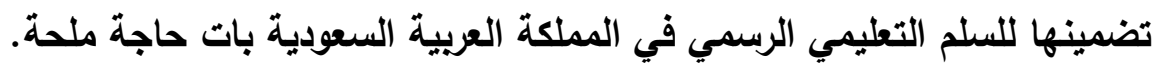
ومن هنا تبلورت مشكلة الدراسة الحالية في السؤال الرئيس ما واقع السلم التعليمي في المملكة العربية السعودية وبين دولة الامارات العربية المتحدة واليابان وفنلندا؟ وتتفرع منه الأسئلة التالية:

- ما واقع السلم التعليمي في المملكة العربية السعودية؟

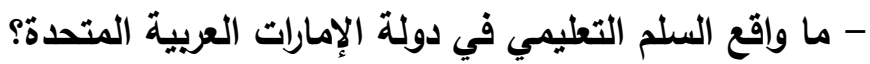
- ما واقع السلم التعليمي في دولة اليابان؟ - ما واقع السلم التعليمي في دولة فنلندا؟ - ما أوجه الشبه والاختلاف بين السلم التعليمي في المملكة العربية السعودية ويين السلم التعليمي في الدول المقارنة؟ مانه - ما إمكانية تظوير السلم التعليمي في المملكة العربية السعودية في ضوء خبرات دول المقارنة؟ 
• التعرف على واقع السلم التعليمي في المملكة العربية السعودية. • التعرف على واقع السلم التعليمي في دولة الإمارات العربية المتحدة. • التعرف على واقع السلم التعليمي في دولة اليابان. • • التعرف على واقع السلم التعليمي في دولة فلنتدا. • تحديد أوجه الثبه والاختلاف في السلم التعليمي لكل من دولة الامارات العربية المتحدة واليابان وفنلندا والمملكة العربية السعودية. • الاستفادة من خبرات الدول المقارنة لتطوير السلم التعليمي في المملكة العربية السعودية.

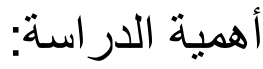

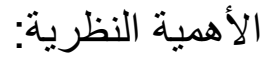
- ق قد تسهم هذه الدراسة المقارنة في إثراء المعرفة من خلال وصف واقع السلم التعليمي وبيان أوجه الثبه والاختلاف بين السلم التطليمي في المملكة العربية السعودية وبين السلم التعليمي في الاول المقارنة. - قد تساعد هذه الاراسة وتضيف للمتخصصين والباحثين المهتمين في مجال الأبحاث المقارنة.

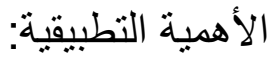
- ق قد تفيد هذه الداسة في معرفة التطور القائم في الاول المقارنة وأثرها على السلم - قد تساعد هذه الاراسة القائمين على التعليم في الاستفادة من التجارب الناجحة وإحداث التغيير المناسب على السلم التطليمي. 
تعتمد الدراسة الحالية على المنهج المقارن باستخدام اسلوب جورج بيريداي ذو الخطوات

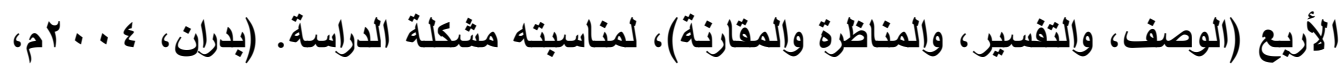
(rov من خلال الخطوات التالية: الوصف: حيث يتم في هذه المرحلة وصف السلم التعليمي في المملكة العربية السعودية ودولة الإمارات العربية المتحدة واليابان وفنلندا، من خلال جمع المعلومات والبيانات التفصيلية في تلاك الدول. التفسير: يتم تفسير العوامل المؤثرة على واقع السلم التعليمي في المملكة العربية السعودية ودولة الإمارات العربية المتحدة واليابان وفنلندا، وتحليل المعلومات في ضوء الاعتبارات الثقافية والسياسية التريوية. المقارنة: حيث يتم الوقوف على أوجه التشابه والاختلاف بين المملكة العربية السعودية ودولة الإمارات العربية المتحدة واليابان وفنلندا في السلم التعليمي، والتعرف على كيفية الإفادة من النه أنماط السلم التعليمي في دول المقارنة بما يتفق مع النظام التعليمي السعودي.

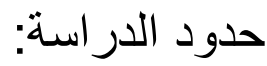
- الحدود الموضوعية: دراسة واقع السلم التعليمي من حيث توزيع سنوات كل مرحلة، ومسارات المرحلة الثانوية، ودور الحضانة ورياض الأطفال في كل من المملكة العربية السعودية ودولة الامارات العربية المتحدة واليابان وفنلندا. - مبررات اختيار دول المقارنة - حصول دولة الإمارات على مراتب متقدمة على المستوى العربي في اختبارات تقييم المعرفة والمهارات في القراءة والرياضيات والعلوم. (البوابة الرسمية لحكومة دولة دلية

$$
\text { الامارات العربية المتحدة، • r • rم). }
$$

- تصدرت اليابان الرابعة دوليا وفق تصنيف بيرسون للخدمات التعليمية، في المهارات

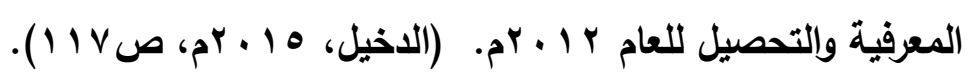


- حقق طلاب فنلندا مراتب متقدمة في • 1 أعوام على التوالي في الاراسات والاختبارات

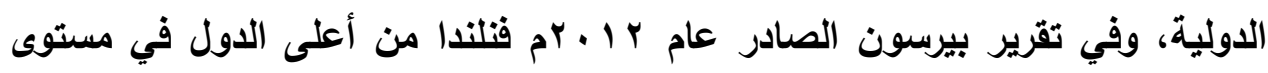

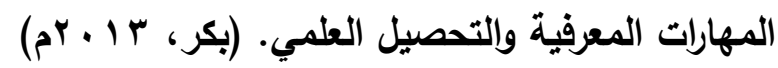

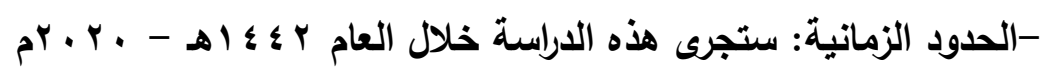

$$
\begin{aligned}
& \text { مصطلحات الدر اسة: }
\end{aligned}
$$

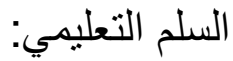

يعرف السلم التعليمي بأنه البنية أو التركيبة التي تتبعها الدولة، لترتيب المراحل الدراسية

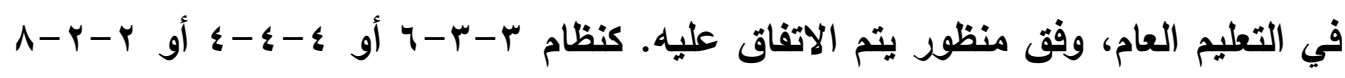

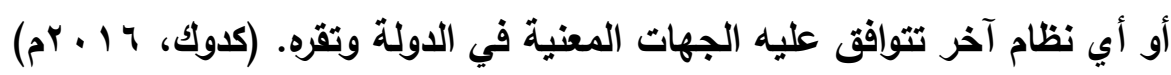

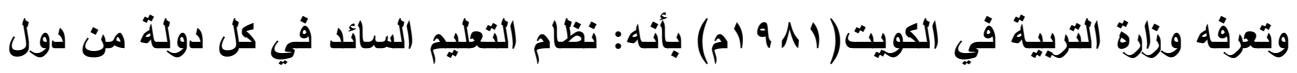
العالم من حيث مراحله المختلفة، وعدد سنوات الدراسة في كل مرحلة، وما يرتبط بذلك من فن فئل سن القبول في كل مرحلة من هذه المراحل. وتُعرف الباحثات السلم التعليمي بأنه: جُزه من كل في النظام التعليمي، يتكون من مراحل

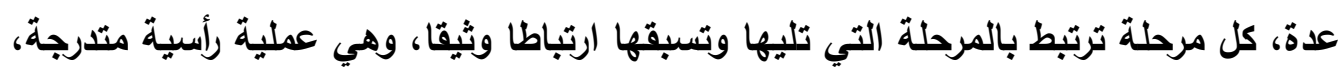
تقرها الدولة وتحدد لها عدد السنوات المناسبة. الإطار النظري للار استة: أولا/مفهوم السلم التعليمي و التعريفات ذات الفرئ العلاقة: السلم التعليمي: هو تنظيم سنوات الدراسة وتقسيمها إلى مراحل تعليمية مرتبطة ومتتالية في شكل سلالم رأسية، وما يترتب على ذلك من تحديد لعدد سنوات الدراسة، وسن القبول وخطة

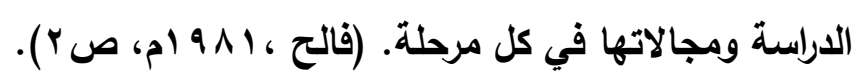

وذكر أنطون (1^ • rم) أن السلم التعليمي هو مراحل الدراسة وفروعها وكيفية توزيعها

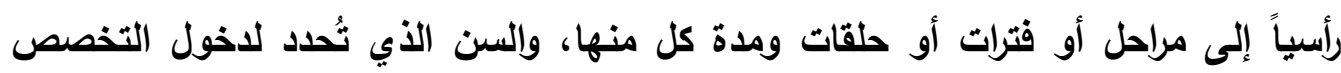
واجتيازه، وكذلك توزيعها أفقياً إلى فروع التعليم المختلفة.

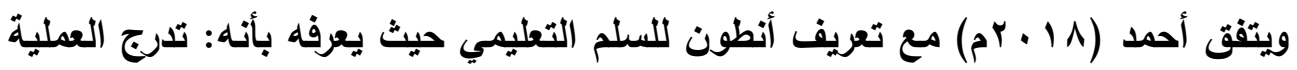
التعليمية التريوية في التعليم النظامي، وتوزيعها رأسيا إلى مراحل وفترات زمنية وحلقات في دئي مراحل دراسية، وسن الاخول لكل مرحلة، وما يتبع ذلك من تخطيط وتتظيم وقوانين. 


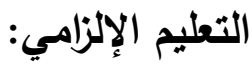

هو "صيغة تعليمية تهدف إلى تزويد كل طفل مهما تفاوتت ظروفه الاجتماعية والاقتصادية والثثافية بالد الأدنى الضروري من المعارف والمهارات والاتجاهات والقيم التي تمكنه من تلبية حاجاته وتحقيق ذاته وتهيئته للإسهام في تنمية مجتمعه". (بكر، 1 ا ـ rم).

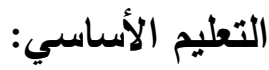

يقصد به التعليم السابق للمرحلة الثانوية، والذي يهلفف إلى الوفاء بالحاجات التطليمية والتتريوية الأساسية وهي المعارف والقيم والاتجاهات.

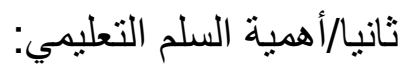
1-يعمل على تنظيم بناء المحتوى الاراسي للمناهج.

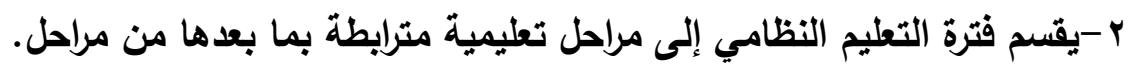

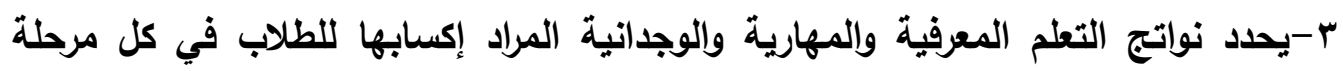
تعليمية.

؛ - يحدد المواصفات التي ينبغي أن تنطبق على المعلمين لكل مرحلة دراسية.

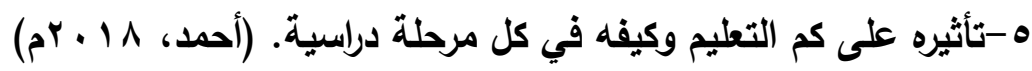

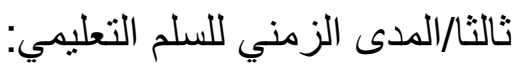
لا يوجد هنالك مدى زمني موحد للسلالم التعليمية، لا بين المراحل الدراسية المختلفة، ولا

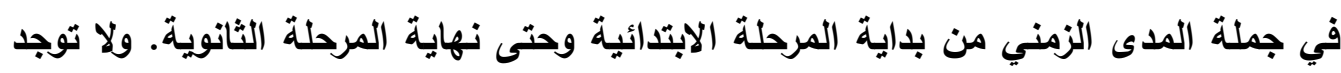

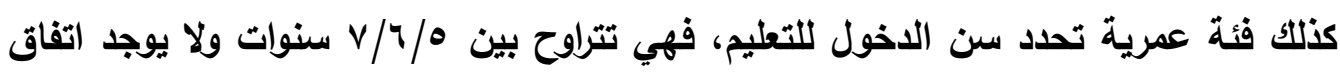

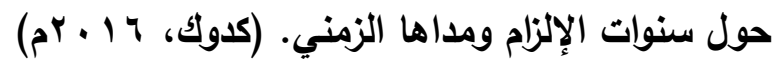
رابعا/مر احل التعليم "السلم التعليمي": رياض الأطفال: هي مؤسسات تريوية تعليمية تستقبل الأطفال في سن ما بين الثالثة والسادسة من العمر، لتوفر لهم الرعاية الثاملة، وتضمن لهم النمو المتكامل والمتوازن جسمياً وعقلياً ونفسياً. مرحلة التعليم الأساسي: الفيا.

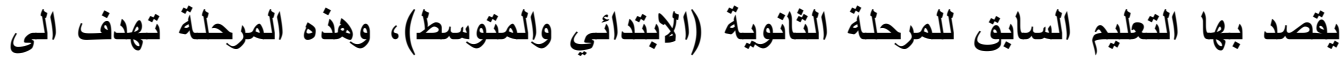
توفير الحاجات التعليمية والتريوية الأساسية وهي: المعارف والمهارات والقيم والاتجاهات. 


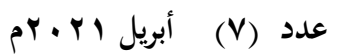
السلم التعليمي في المملكة العربية السعودية.

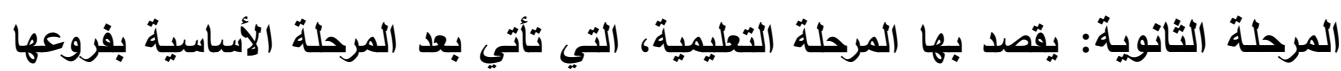

$$
\begin{aligned}
& \text { الأدبية والعلمية والصناعية والتجارية. (أحمد، } 1 \text { ا + rم). } \\
& \text { الدر اسات السابقة: }
\end{aligned}
$$

هناك العديد من الدراسات التي ترتبط بالدراسة الحالية ارتباطا وثيقا، ودراسات أخرى مرتبطة ارتباطا غير مباشر ونستعرض منها الاراسات التالية:

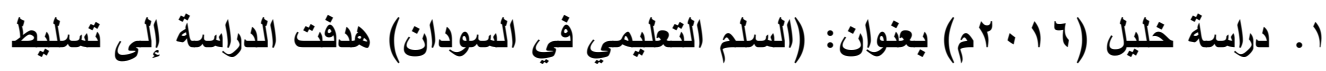

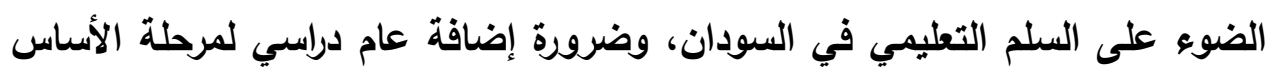
لتصبح تسع سنوات.

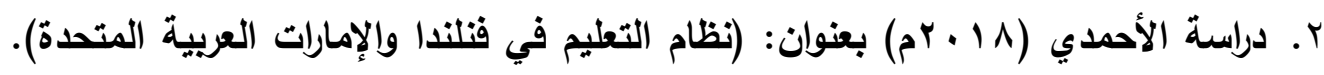
هدفت هذه الدراسة إلى وصف وتحليل نظام التعليم في كل من فنلندا والإمارات العربية

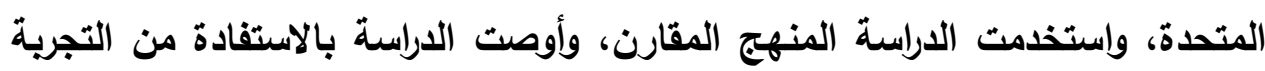
الفتلندية في توظيف التعليم في خدمة الاقتصاد.

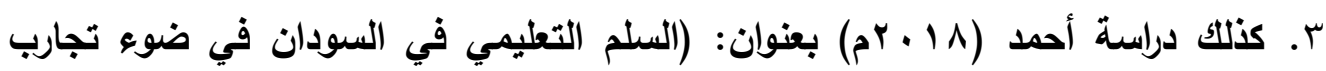
الدول العربية ويعض الدول الأجنبية) استذدمت الاراسة المنهج الوصفي التحليلي المقارن وتهدف إلى التعرف على واقع السلم التعليمي في السودان، وعلى وتوصلت التئل

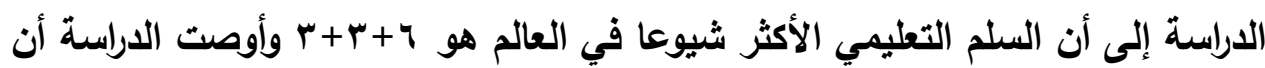
على وزارة التربية والتعليم النظر في تطبيق السلم التعليمي السابق نظرا لمراعاة الاعتبارات النفسية فيما يتعلق بمراحل النمو والاستعداد النفسي للطلاب.

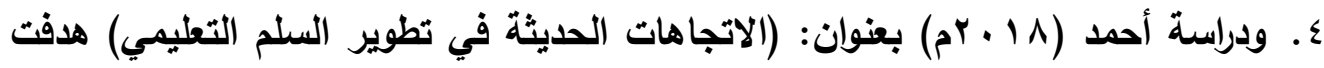

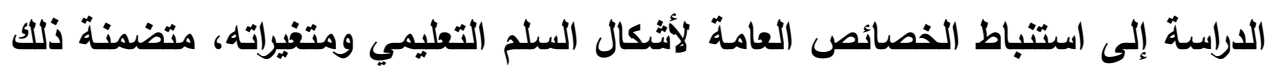

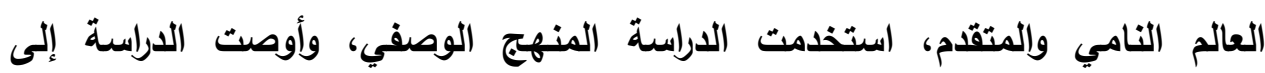

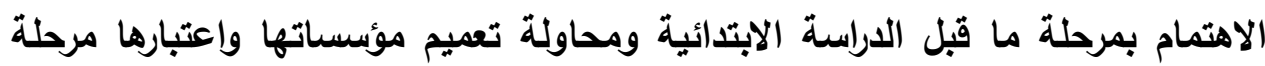
تعليمية ضمن مراحل سلم التعليم العام. 0. ودراسة دياب (10 ب بم)، بعنوان: (النظام التعليمي في جمهورية نيجيريا الاتحادية بين آثار الماضي وتحديات المستقبل)، وتناولت الدراسة السلم التعليمي في نيجيريا ومراحل 


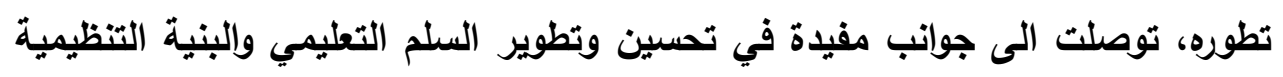

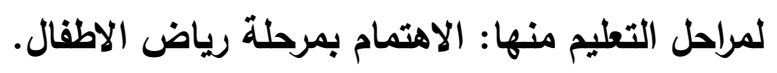
التعقيب على الدر اسات السابقة:

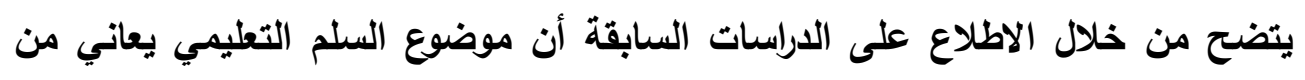

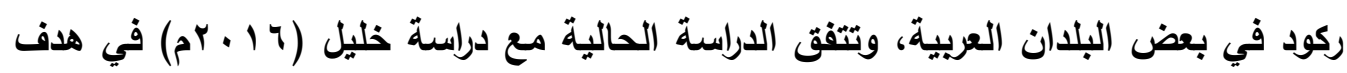

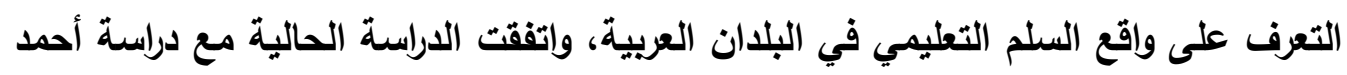

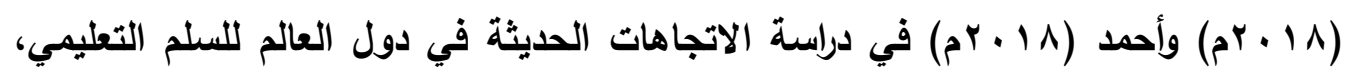

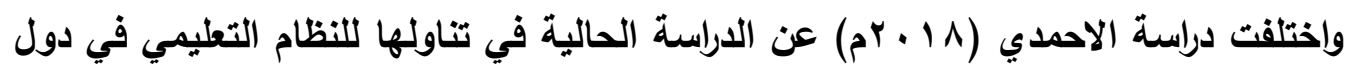

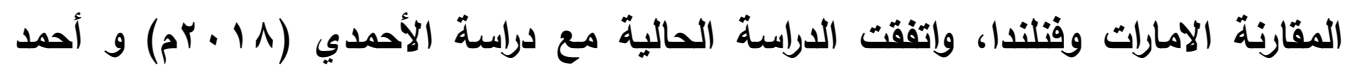

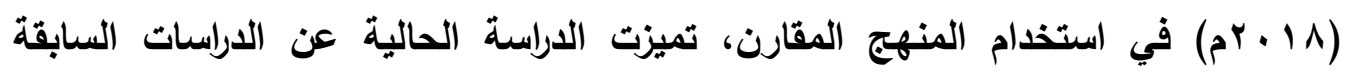

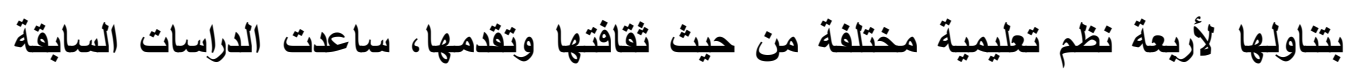

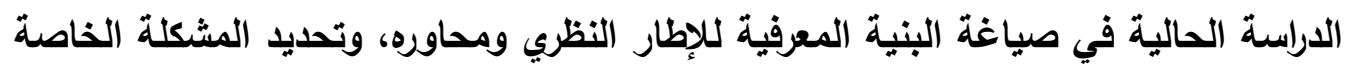

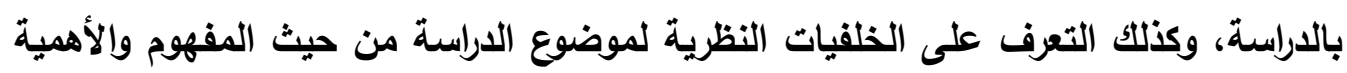
والتجارب الدولية حوله، تحديد المنهج المستخدم في الداراسة الحالية.

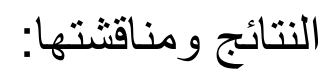
السؤال الأول: ما واقع السلم التعليمي في الملكة العربية السعودية؟ سيتم الإجابة على هذا السؤال من خلال عرض مختلف جوانب السلم المالم التعليمي في المملكة

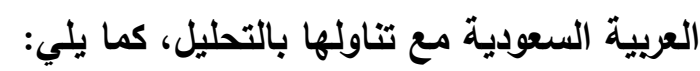

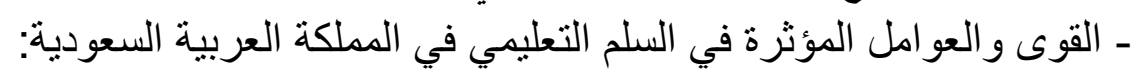

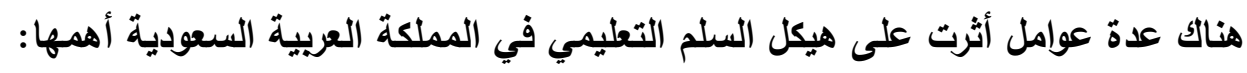

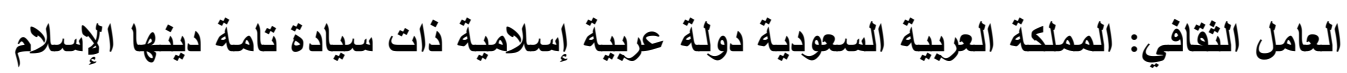
ودستورها كتاب الله تعالى وسنة رسوله صلى الله عليه وسلم ولغتها هي اللغة العربية.

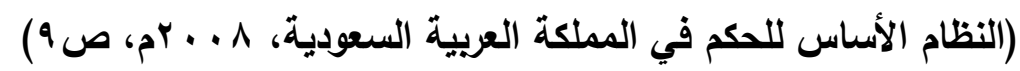

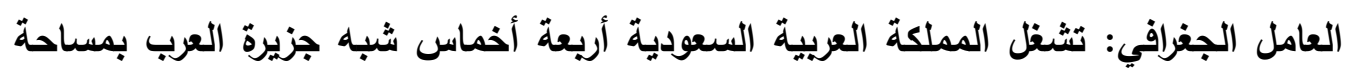

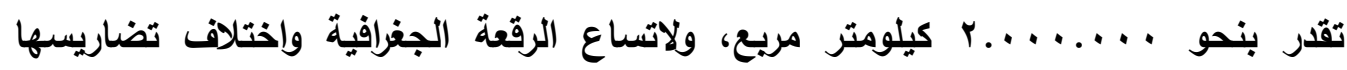




\section{عدد (V)} السلم التعليمي في المملكة العربية السعودية...

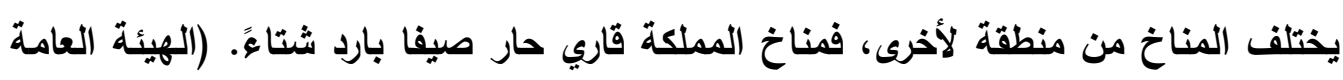

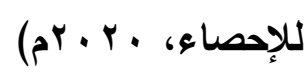
العامل التاريخي: تثكل وثيقة سياسة التعليم في المثلكة العربية السعودية عامل مؤثر في

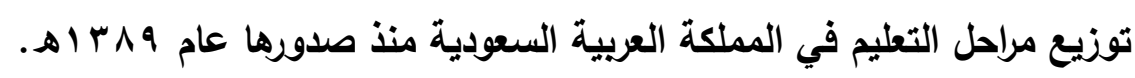

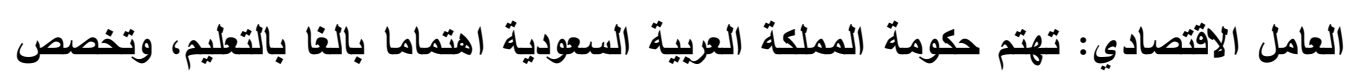

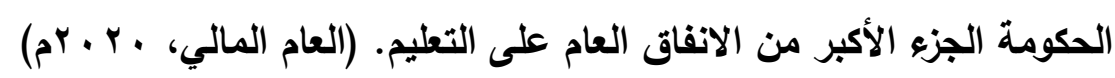

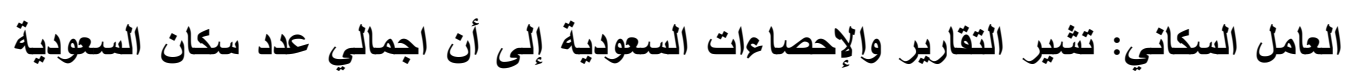

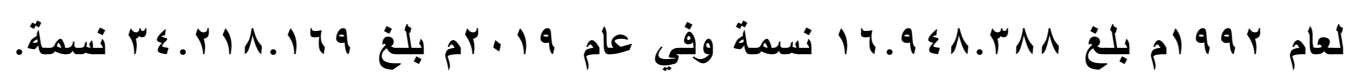

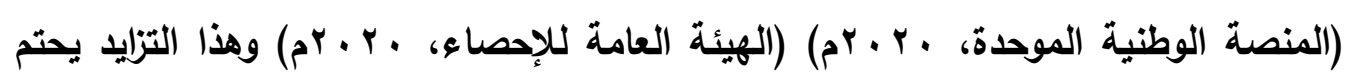

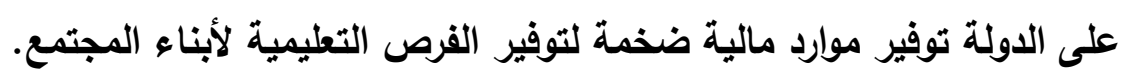
- هيكل السلم التعليمي في دولة المملكة العربية السعودية:

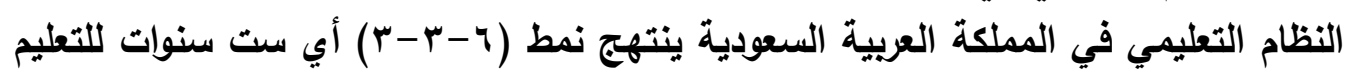

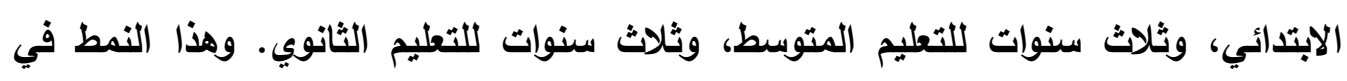

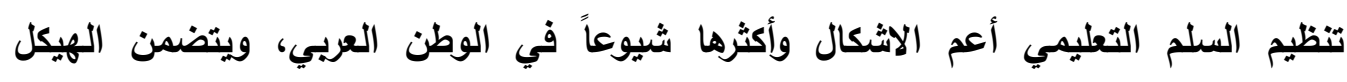

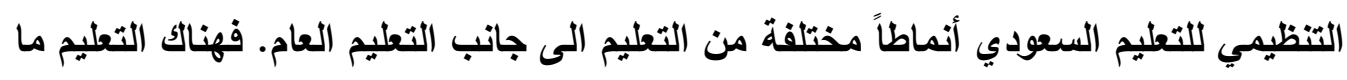

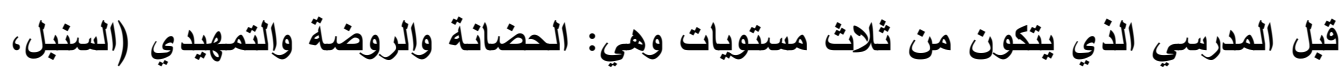

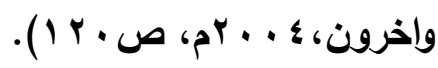

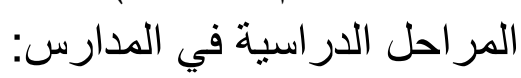

$$
\begin{aligned}
& \text { مرحلة ما قبل الابتدائي: }
\end{aligned}
$$

التعليم ما قبل الأساسي، للأطفال دون السادسة من العمر، ولا يعد إلزاميا، ويتم تقليمه

$$
\text { المبر الروضات الابتدائية: }
$$

تتكون من ست سنوات دراسية، بدءا من عمر • سنوات وستة أثهر أو ست سنوات.

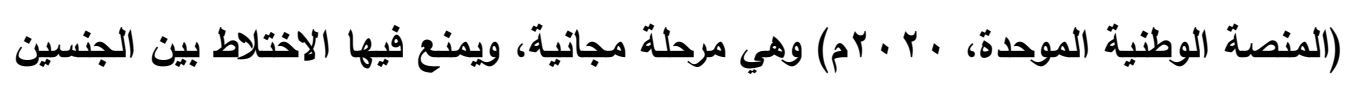

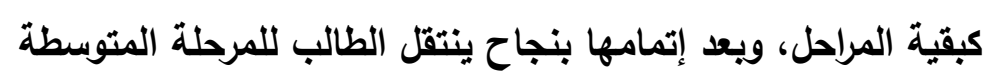

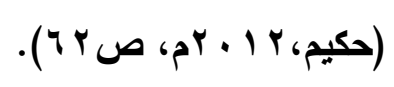


المرحلة المتوسطة:

المرحلة المتوسطة هي الحلقة الوسطى من حلقات التعليم العام، يلتحق بها الطالب بعد

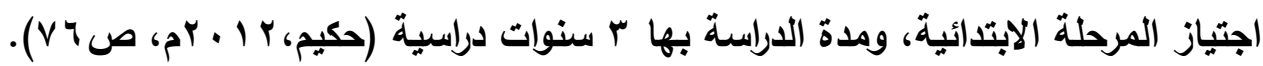

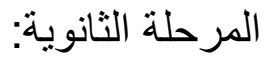

تتكون من ثلاث سنوات دراسية، كما تقدم المعاهد الصناعية ومعاهد العمارة والتثييا

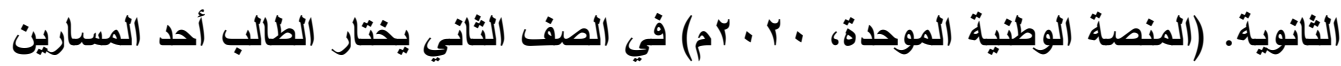
العلمي أو الأدبي، وهناك نظام المقررات الذي يشمل المرحلة الثانوية بأكملها. والمعاهد الصناعية والعمارة والتشييد الثانوية هي خيار تضعه برامج التدريب التقني والمهني للطالب الذي أنهى المرحلة المتوسطة في أن يلتحق في مسارات فنية وصناعية.

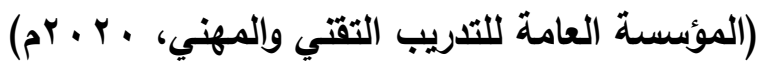

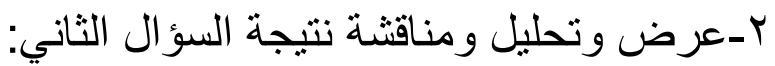

السؤال الثاني: ما واقع السلم التعليمي في دولة الإمارات العربية المتحدة؟ سيتم الإجابة على هذا السؤال من خلال عرض مختلف جوانب السلم التعليمي في دولة

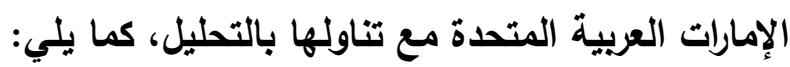

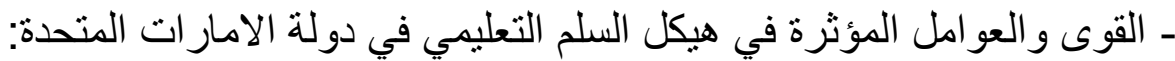
العوامل الثقافية: يشكل الإسلام الدين الرسمي في دولة الإمارات، كما يسمح بمُ بمُمارسة المعتقات الدينية الأخرى، وتعد اللغة العربية هي اللغة الرسمية في المؤسسات واللهيئات الحكومية (حكومة دولة الإمارات العربية المتحدة، • r • rم). العوامل السياسية: تعد الإمارات العربية المتحدة دولة اتحادية دستورية مكونة من سبع إمارات وتتمتع بسيادة كاملة، يقوم النظام السياسي للاولة على خمس سلطات: المجلس الأعلى للاتحاد، رئيس الاتحاد ونائبه، مجلس الوزراء، المجلس الوطني الاتحادي، القضاء

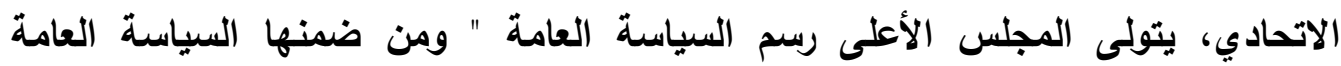

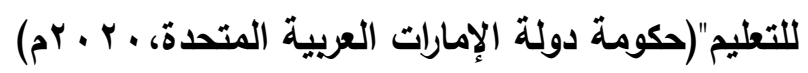
العوامل الاقتصادية: تحظى الامارات باقتصاد مستقر ومتنوع، يمتاز بالمرونة في تبنى النماذج الاقتصادية الجديدة والاستفادة من الشراكات العالمية، بما يكفل الازدهار والرخاء للأجيال الامارتية الحالية والقادمة، تواصل الحكومة في جهودها في الانتقال إلى اقتصاد قائم على بلى

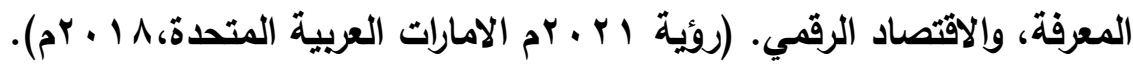


العوامل الجغرافية: تقع دولـة الإمارات العربية المتحدة في قارة آسيا، وتبلغ مساحة الدولة

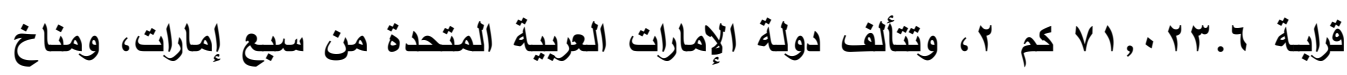
دولة الإمارات صحراوي دافئ ومشمس شتاءً، وحار ورطب صيفاً (حكومة دولة الإمارات

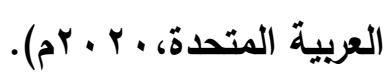
العوامل السكانية: وفقاً للمركز الاتحادي للتنافسية والإحصاء، بلغ العدد الإجمالي لسكان دولة

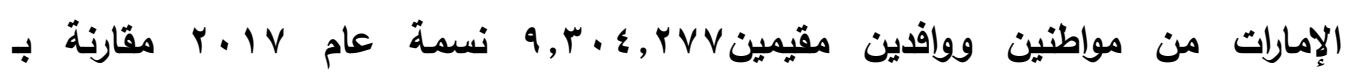

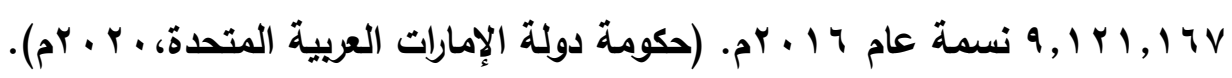
هيكل السلم التعليمي في دولة الإمار ات العيمة عام العبية المتحدة:

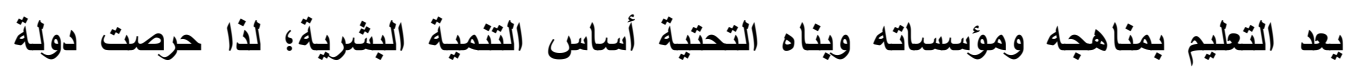
الإمارات العربية المتحدة في خططها التنموية التطويرية على وضع التعليم محل الصدارة، ولناه حيث ان مكانة الدولة وخططها التنموية وتنوعها الاقتصادي القادر على المنافسة إنما تقوم

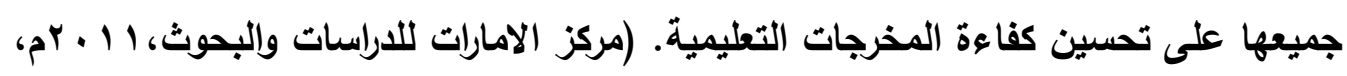
ص 1 ) وقسمت وزارة التربية والتعليم السنة الدراسية إلى ثثلاثة فصول دراسية. (البوابة الامات

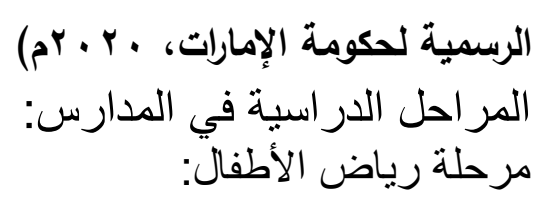
تعد الدراسة في مرحلة رياض الأطفال غير إلزامية، ويلتحقون بفصول مختلطة مدتها عامان كما بلي: تعلي

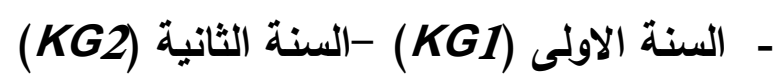
وفي هذه المرحلة يتم إعداد الأطفال قبل دخولهم الحلقة الأولى وما بعدها، ويجد الطالب البالبه وقتاً في تنمية مهاراته الاجتماعية، واللغوية، والبدنية، والأكاديمية (حكومة دولة الإمارات

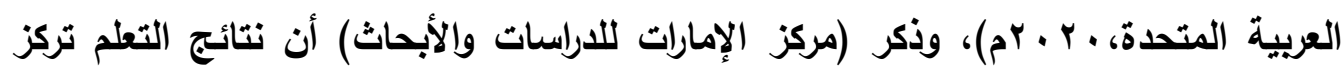
على المعرفة والقهم، وسلوكيات التعلم، ومهارات التعلم التي ستوفر الأساس للتعلم الناجح

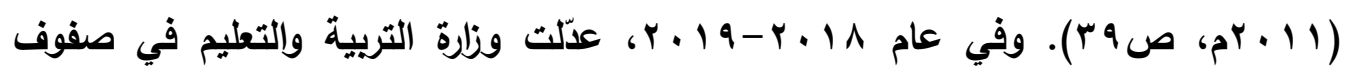
المراحل الدراسية، بحيث يكون عدد الصفوف في كل مرحلة أربعة سنوات، وذلك على النحو التالي: 
المرحلة التأسيسية المستوى الابتدائي:

تثمل هذه المرحلة الصفوف الدراسية من الأول إلى الرابع، وتهاف إلى توفير بيئة تعليمية غنية تسهم في تثجيع الطلبة على التعلم، وتساعدهم في بداية مشوارهم الدراسي. المرحلة المتوبطة: يكمل الطلبة في هذه المرحلة الصفوف الاراسية من الخامس حتى الثامن، وتهدف إلى رعاية الطلبة وتأهيلهم للمستقبل، ومساعدتهم في تنمية الشعور بالولاء للمجتمع (حكومة دولة

$$
\text { الإلمارات العربية المتحدة، • r • r م). }
$$

تثمل هذه المرحلة الصفوف الاراسية من التاسع حتى الثاني عشر، ويتهيأ الطلبة في هذه المرحلة التعليمية لبداية حياتهم العملية وتقلُّ أدوارهم في المجتمع، ويمجرد الانتهاء من هذه هنه

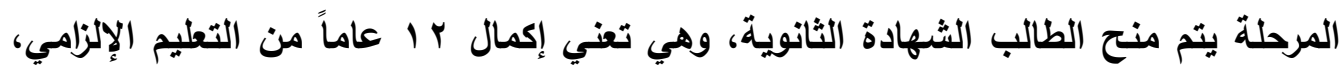
ويمُنح الطلاب الذين أكملوا تعليمهم في المدرسة الثانوية التقنية الدبلوم القني الثانوي. (حكومة دولة الإمارات العربية المتحدة، • ب • r م). مسارات التعليم في المدراس الحكومية: قسمت التعليم الثانوي إلى أربع مسارات:

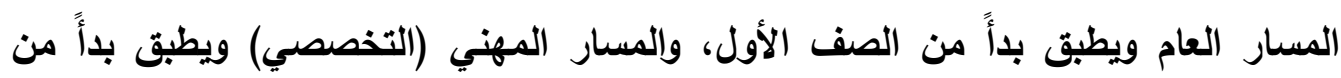
الصف التاسع، والمسار المتقدم من الصف العاشر ويحق فيه للطالب الالتحاق بالمسار

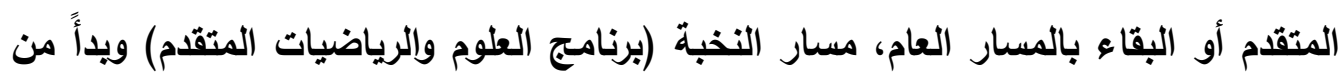
الصف السادس بحق للطلاب المميزين علمياً الالتحاق به (حكومة دولة الإمارات العربية

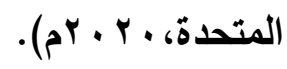

نظام الدراسة بمرحلة التعليم الأساسي بلولة الأمارات:

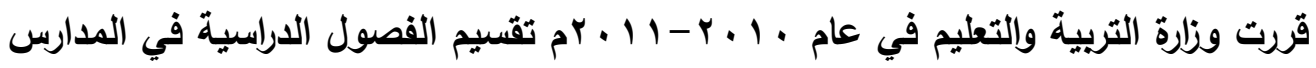
الخاصة والحكومية إلى ثلاثة فصول دراسية، مع المحافظة على أيام السنة الدراسية في

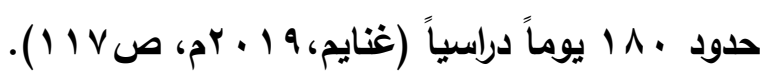




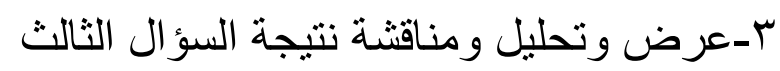

- السوال الثالث: ما واقع السلم التطليمي في دولة اليابان؟

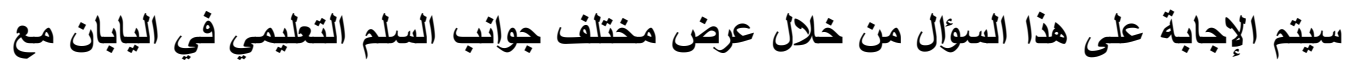

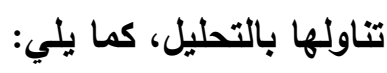

- القوى والعوامل المؤثرة في هيكل السلم التعليمي في اليابان:

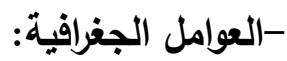

تتكون اليابان من ثلاثة آلاف جزيرة، بالإضافة إلى أريع جزر كبيرة وعدد محافظاتها

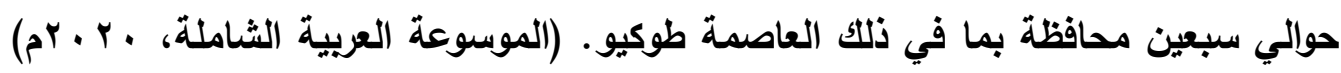

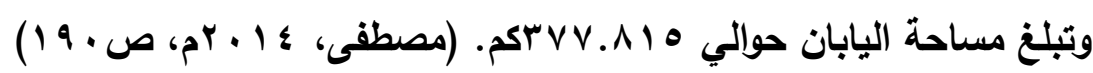

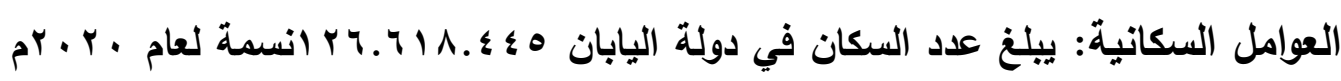

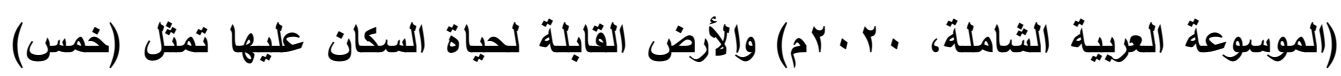

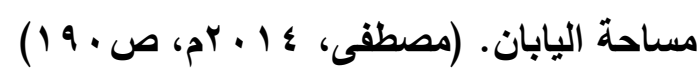
العوامل الاقتصادية: جاءت معجزة اليابان الاقتصادية بعد الحرب العالمية الثانية إلى نظامها

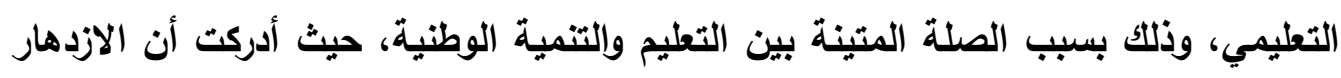

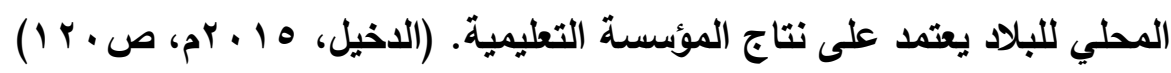

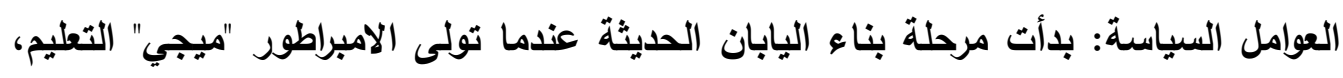

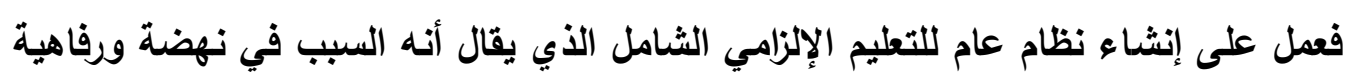

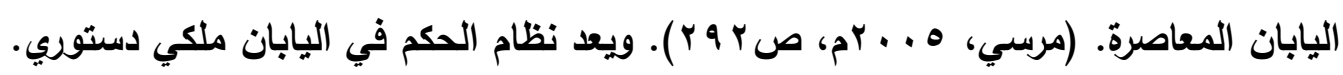

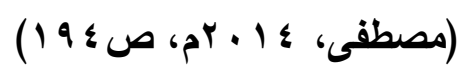
هيكل السلم التعليمي في دولة اليابان:

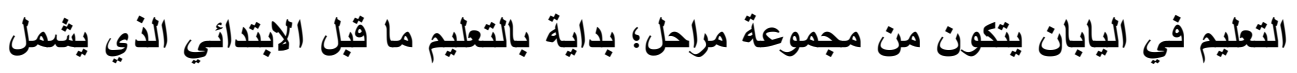

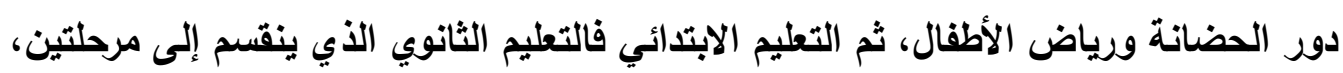

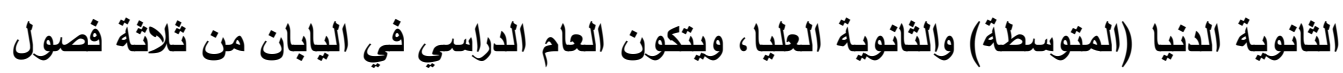

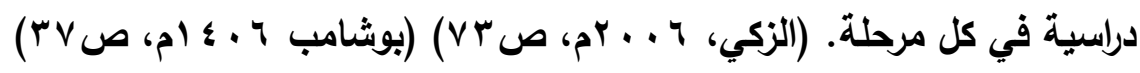




$$
\text { أولا: التعليم قبل الابتدائي: }
$$

يتكون التعليم قبل الابتدائي في اليابان من مؤسستين مؤسسة رياض الأطفال ودور

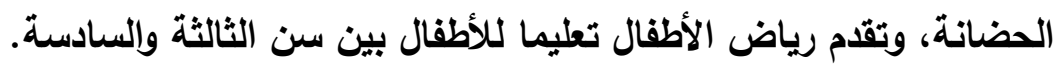
ومؤسسات التعليم ما قبل المدرسة ليست إلزامية، حيث هدفها هو مساعدة الأطفال على فئل أن ينمو عقولهم وأجسامهم وذلك عن طريق تنشئتهم في بيئة تعليمية تريوية صالحة

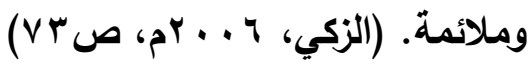

$$
\begin{aligned}
& \text { رياض الأطفال: }
\end{aligned}
$$

مدتها ثُلاث سنوات من سن الثاثثة إلى سن السادة، وهو تعليم اختياري غير مجاني

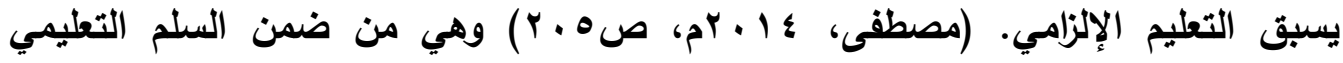

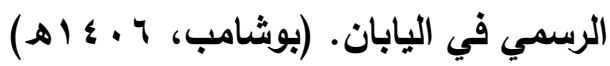

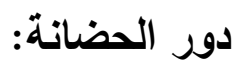

هي نظم أعدت كمؤسسات الخدمة الاجتماعية للأطفال بالاتفاق مع قوانين تنظيم الذدمة

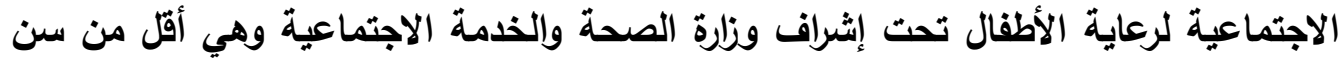

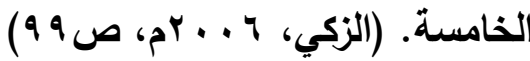

$$
\begin{aligned}
& \text { مرحلة التعليم الإلزامي: }
\end{aligned}
$$

مرحلة التعليم الابتدائي: مدتها ست سنوات، يدخلها جميع الأطفال عند بلوغهم ست سنوات،

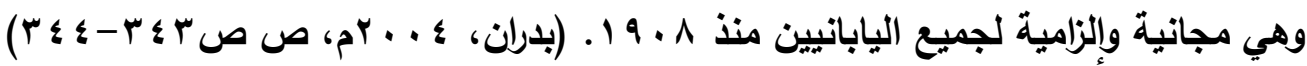
مرحلة التعليم المتوسط (الثانوية الانيا) يلتحق الأطفال بالثانوية الدنيا بعد إنهائهم للاراسة بالمدرسة الابتدائية، ومدة الدراسة بهانيا

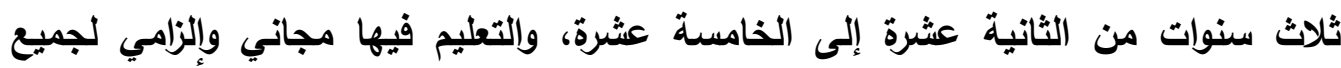

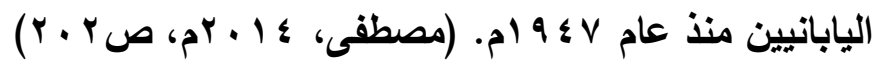
مرحلة التعليم الثانوي (الثانوية العليا)

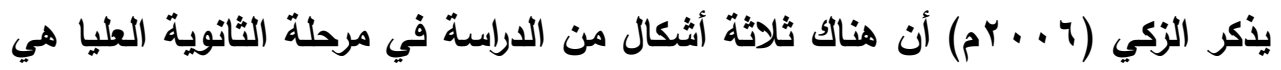

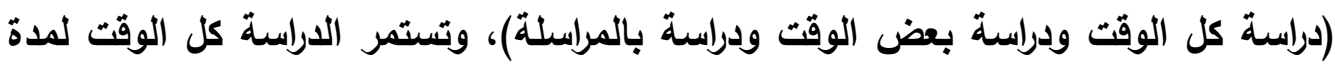

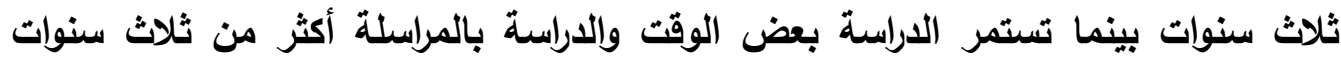


وتقدم الدراسة بعض الوقت في الفترات المسائية في فترة بعد الظهر والفترات المسائية. (ص ( $\vee v-v q$ السؤال الرابع: ما واقع السلم التعليمي في دولة فنلندا؟ سيتم الإجابة على هذا السؤال من خلال عرض مختلف جألف جوانب السلم التعليمي في فنلندا مع تناولها بالتحليل، كما يلي: - القوى و العوامل المؤثرة في السلم التعليمي الفنلندي:

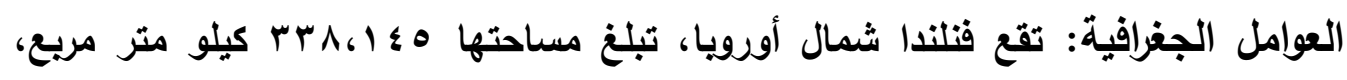
وتعد الغابات من اهم مواردها الطبيعية، وكنلك تمتلك المحاصيل الزراعية والحيوانية ومنتجات الالبان واللحوم، ولايها النحاس والماكينات ويناء السفن ومنتجات الاخثاب وصناعة وكاتهات المعادن

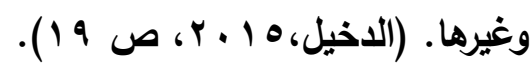

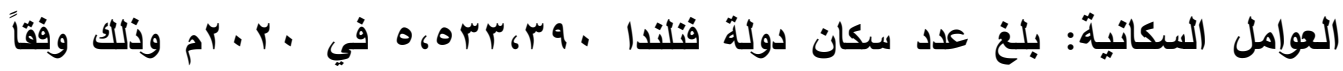

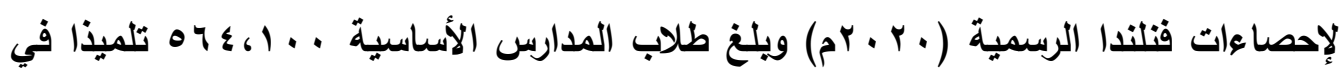

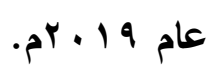
العوامل الثقافية: في فنلندا يتحدث 9،ءمليون من السكان باللغة الام وهي اللغة الفتلندية

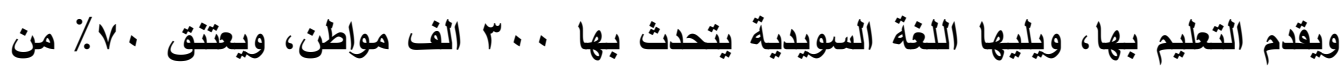

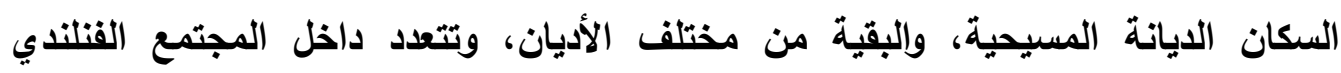

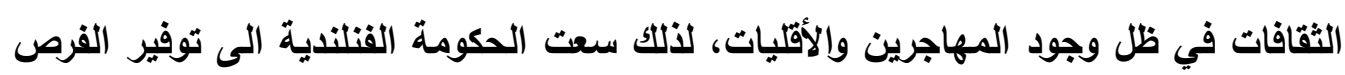

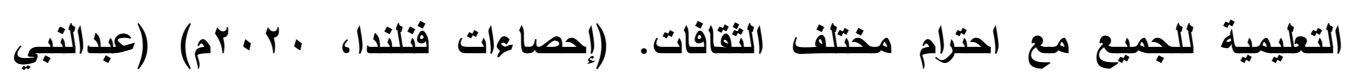

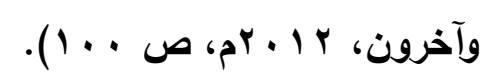

العوامل الاقتصادية: خلال فترة النمو الاقتصادي في الثمانينات أصبحت فنلندا من أغنى

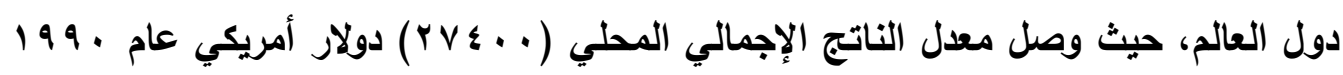

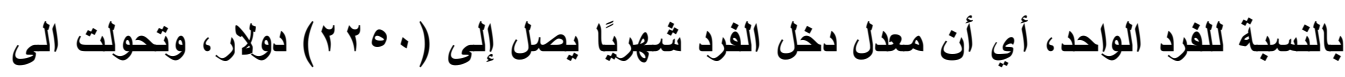

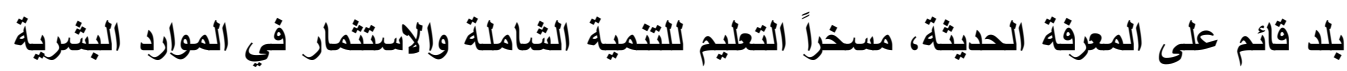

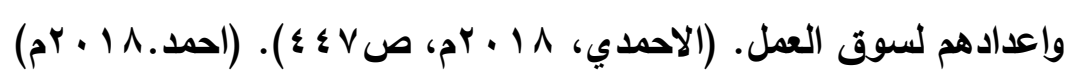


العوامل السياسة: تقوم دولة فنلندا على أسلوب الديمقراطية في سياستها، ولديها علاقات خارجية جيدة، ساهمت في تطوير التعليم وسهت لها المشاركة في البرامج والمسابقات

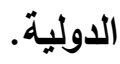

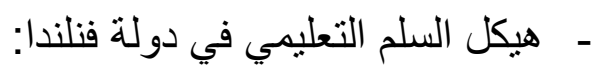

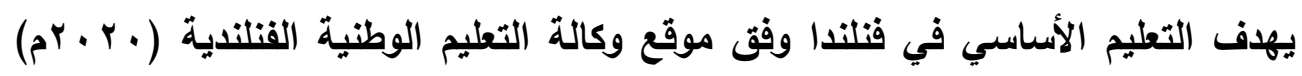

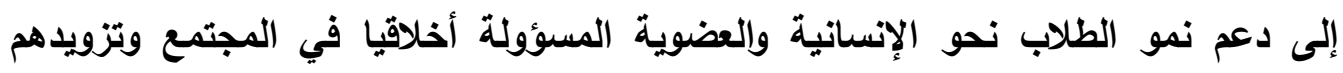

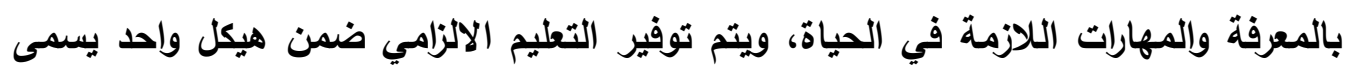

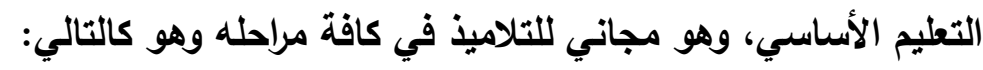

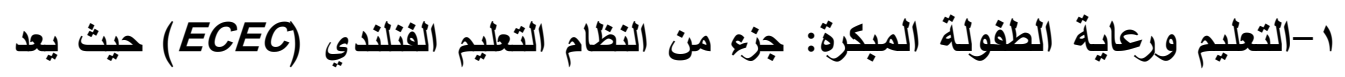
الأساس وفق مبأ التعلم ددى الحياة، مع التركيز الخاص على الطعلى أصول التدريس، ويتمتع

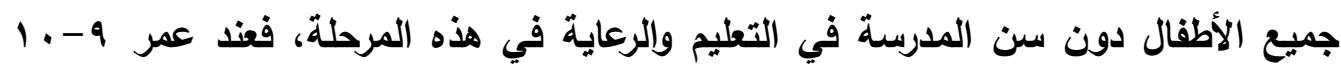

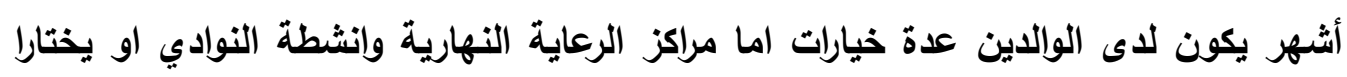

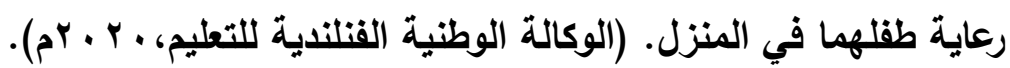

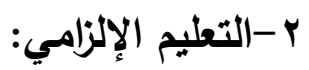

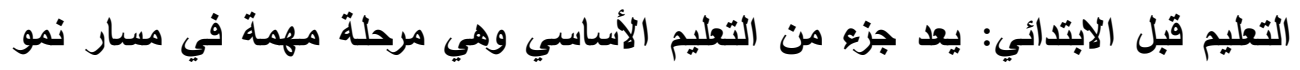

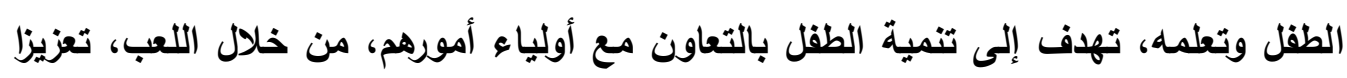

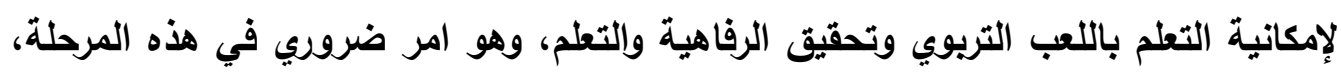

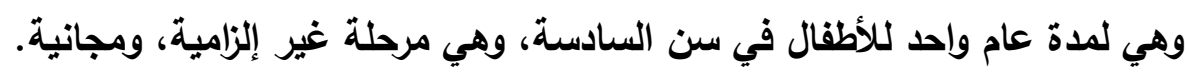

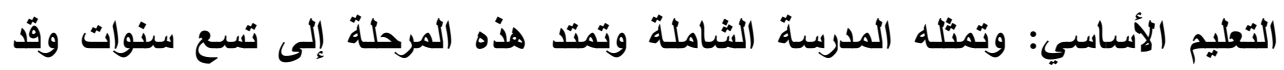

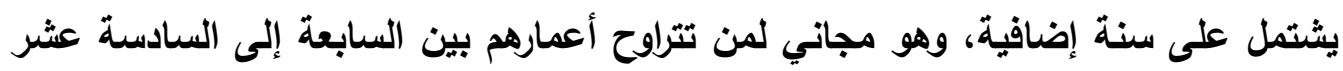

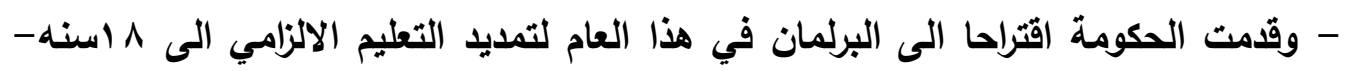
وحاليا هو كالتالي: المرحلة الابتدائية: تستمر نحو 1 سنوات يبدأها التلاميذ من عمر السابعة الى الثانية عشر

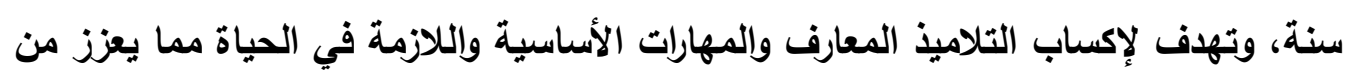
فرص نجاحهم في المراحل اللاحقة لتعليمهم. 


$$
\text { ب-التعليم بعد الالزامي: }
$$

- التعليم الثانوي العام: وعندما يكمل الطالب منهج المدرسة الثامل يتم قبوله في التعليم الثانوي حيث يتوفر للطالب معرفة عامة استعدادا للجامعة ويمتد لثلاث سنوات، وهو مجاني، باستثناء الكتب والمواد التعليمية، وعند اتمامها يكون مؤهل لامتحان القبول الوطني الفنلندي.

- التعليم المهني: يقدم فيه التعليم والتدريب في سبع مؤهلات مختلفة يخضع فيها الطالب

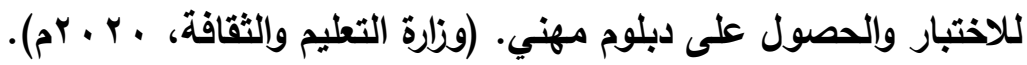
تحليل وتفسير القوى والعوامل المؤثرة في السلم التعليمي في المملكة العريية السعودية

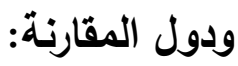
في اليابان تتعدد أنماط الدراسة تبعا للعوامل الجغرافية والسكانية فتضاريس اليابان الجبلية تشكل عائق في وصول الطلاب إلى المدارس بشكل منتظم ومع التعداد السكاني الضخم؛ دعا الأمر إلى وجود نمط للاراسة وهو الدراسة بالمراسلة، والدراسة بعض الوقت، وذلك ليتسنى للجميع الحصول على فرصنهم في التعليم.

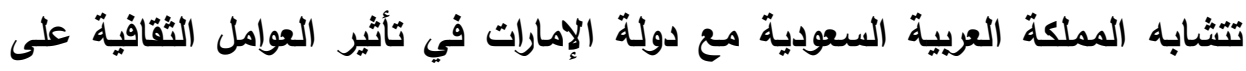
النظام التعليمي، فالدين الإسلامي واللغة العربية يشكلان ركائز مهمة في التعليم في كلا البلاين، ويشكل الدين الإسلامي بسنته النبوية مصدر يستقى منه في تأصيل مبدأ

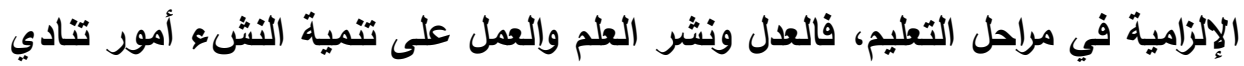
بها الشريعة الإسلامية، وتختلف اليابان وفنلندا مع المملكة العربية السعودية والامارات المتحدة في أهمية الجانب الديني في مراحل التعليم وذلك يرجع لايمقراطية النظام واحترام تعددية الأعراق بلياناتها ومذا هبها المختلفة. تختلف دولة المملكة العربية السعودية عن دول المقارنة في العامل الاقتصادي، فالاقتصاد في الدولة المحلية قائم على النفط ولا يرتبط الاقتصاد هنا بتوزيع مراحل التعليم بخلاف اقتصاد دولة الامارات القائم على مصادر متعددة منها النفط والاتجاه نحو الاقتصاد الرقمي والاقتصاد القائم على المعرفة، شجع الاهتمام بالاقتصاد الرقمي

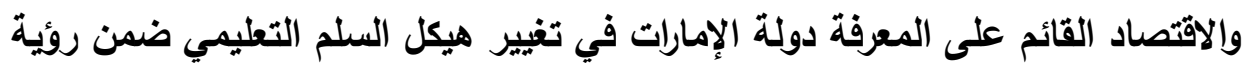

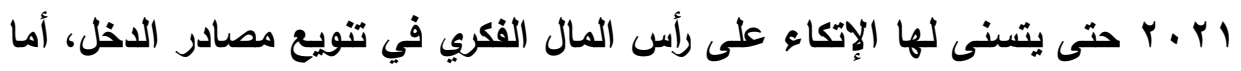




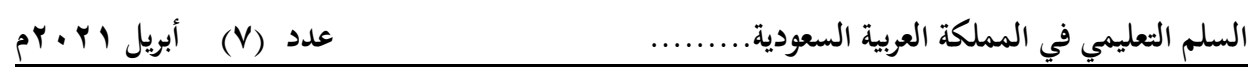

في فنلندا فالاقتصاد قائم على المعرفة والابتكار، ولعل هذا الأمر له علاقة بجعل المرحلة الثانوية مرحلة مهنية بامتياز تعد فيها الكوادر البشرية باكرا، وفي اليابان فالاقتصاد قائم على التصنيع، وهو بالتالي قد لا يشكل تأثير على توزيع السلم التعليمي في النظام التعليمي الياباني. تثكل البقعة الجغرافية واتساعها في المملكة تأثير في عملية انتشار رياض الأطفال في أنحاء المملكة العربية السعودية، وفي توزيع برامج التدريب التقني والمهني في الهجر والمحافظات، بينما ساعدت المساحة فنلندا مع تعدادها السكاني القليل في بوري تجويد عملية التعليم والاهتمام بمرحلة العضانة ورياض الأطفال وتعميمها، وأما دولة الإمارات فقد يكون تعدادها السكاني وتعدد أماراتها ساهم في التركيز على تجويد المرحلة الثانوية وجعلها مرحلة لتخريج كفاعات يقوم عليها اقتصاد الدولة. - تثكل وثثقة سياسة التعليم في المملكة العربية السعودية عامل تاريخي مؤئر في ركود

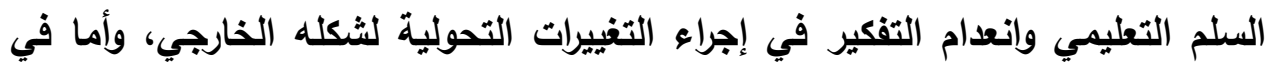
دول المقارنة لا تشكل الجذور التاريخية أي تأثير في هيكل السلم التعليمي.

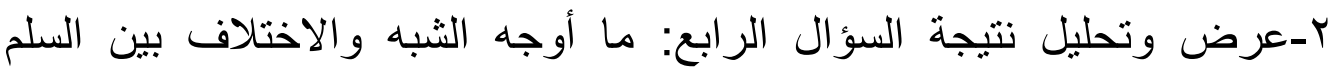

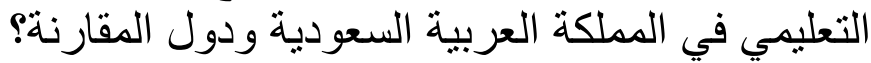

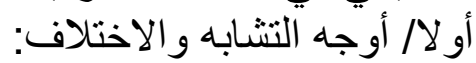

تتثابه المملكة العربية السعودية مع دول المقارنة في مجانية والزامية التعليم للمراحل الاراسية للتعليم العام. وتتثابه المملكة العربية السعودية مع فنلندا من حيث وجود جانب مهني بعد المرحلة المتوسطة. إلا أن الجاتب المهني في المملكة اختياري وليس أمر رسمي، على خلاف فنلندا فهذه المرحلة مرحلة أساس في السلم التعليمي. وتتثابه كل من المملكة العربية السعودية وفنلندا واليابان في توزيع مراحل السلم التعليمي، وتتثابه الدولة المحلية مع فنلندا في نمط التعليم المهني الغير إلزامي. وتتثابه اليابان مع دولة الإمارات العربية المتحدة في وجود ثلاثة فصول دراسية للعام الواحد، بخلاف المملكة العربية السعودية وفنلندا. 


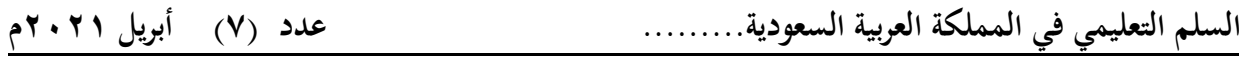

$$
\begin{aligned}
& \text { رياض الأطفال ودور الحضانة: }
\end{aligned}
$$

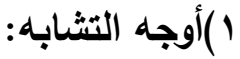

في المملكة العربية السعودية والإمارات المتحدة واليابان وفنلندا التعليم ما قبل الأساسي غير إلزامي يقوم عليه القطاع الحكومي والخاص، إلا أن اليابان وفنلندا ركزوا على هذه المرحلة من حيث الإعداد في المناهج والاتجاهات الإيجابية حولها، أيضا اليابان وفنلندا جعلت من تلكك المرحلة جزء أساس في السلم التعليمي.

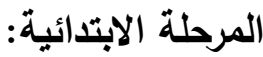
(أوجه التثابه: المرحلة الابتدائية في المملكة وفي اليابان وفنلندا عدد سنوات تحقيقها هو ستة أعوام.

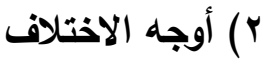

عدد سنوات المرحلة الابتدائية في دولة الإمارات العربية المتحدة هو ع سنوات. المرحلة المتوسطة:

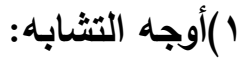
في المملكة العربية السعودية وفي اليابان وفي فنلندا عدد سنوات المرحلة المتوسطة هو تثلاثة أعوام وتسمى في اليابان الثانوية الدنيا، وفي فنلندا تسمى التعليم الثانوي العام.

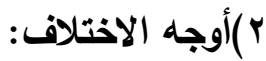
في دولة الإمارات العربية المتحدة عدد سنوات المرحلة المتوسطة هو أربعة أعوام.

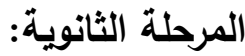
(أوجه التشابه: المملكة العربية السعودية واليابان يتثابهان في عدد سنوات المرحلة الثانوية.

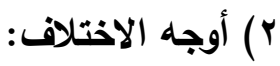
- في المملكة العربية السعودية وفي المرحلة الثانوية هناك مسار المقررات لسائر المرحلة، وهناك مسار الأدبي والعلمي بعد السنة الأولى من المرحلة الثانوية يستمر للسنتين الاخيريتين. وهناك المعاهد الصناعية والعمارة والتشييد وهي اختيارية بعد المرحلة المتوسطة، تعنى بالجانب المهني المهاري. 


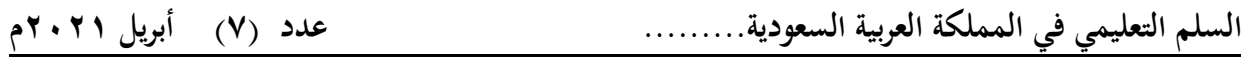

-في دولة الإمارات التعليم في المرحلة الثانوية يمتد لأريعة أعوام، وهناك أريع مسارات في تلك المرحلة تركز على تميز الطلاب وتجويد مخرجاتهم الاكاديمية.

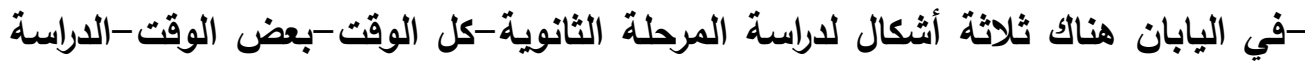

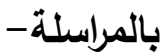

-في فنلندا يحل الجانب المهني محل المرحلة الثانوية تقدم فيها سبع مسارات اختيارية للطلبة بغرض تقديمهم لسوق العمل بشكل مبكر، وتتدرج تحت مسمى الابلوم المهني. ثانيا/ ما تمبزت به دول المقارنة و الدولة المحلية:

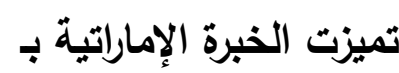

-دولة الامارات من بين دول المقارنة والدولة المحلية المتفردة بشكل السلم التعليمي الظاهري (ع - - - ) وتميزت عن المملكة بتخليها عن مسار الأدبي والعلمي واستحداث

$$
\begin{aligned}
& \text { مساري المهني التخصصي والنخبة. } \\
& \text { تميزت خبرة اليابان بـ }
\end{aligned}
$$

اليابان من بين دول المقارنة والدولة المحلية التي تفردت في تنويع أنماط الدراسة في المرحلة الثانوية.

$$
\text { تميزت الخبرة الفتلندية بـ }
$$

تميزت فنلندا عن المملكة ويقية دول المقارنة بالاهتمام بمرحلة رياض الأطفال والحضانة مع وجود مناهج تقوم على تعليم الطفل ما يحتاجه من المعارف واللطوم، ومع وجود سنة إلزامية قبل مرحلة التعليم الأساسي.

واختلفت المملكة العربية السعودية وجميع دول المقارنة في السن الالزامي للاخول للمدرسة، فالمملكة العربية السعودية سن الاخول لمرحلة الابتدائية في عمر الخمس سنوات وستة أشهر، والإمارات واليابان يستلزم دخول الطالب فيها إلى المرحلة الابتدائية عند سن 1 الابله سنوات، وفي فنلندا الاخول للمرحلة الابتدائية عن عمر V سنوات. 


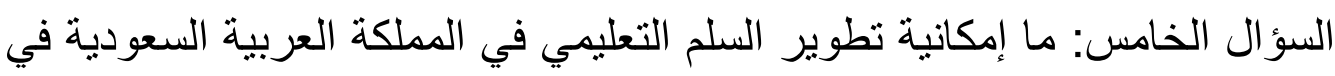

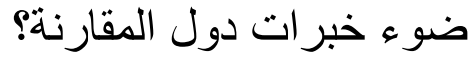

من خلال استعراض واقع السلم التعليمي في كل من المملكة العربية السعودية ودولة الامارات العربية المتحدة واليابان وفنلندا، وتحديد أوجه الشبه والاختلاف بينها يمكن القول ان السلم التعلمي في المملكة العربية السعودية يمكن تطويره من خلال:

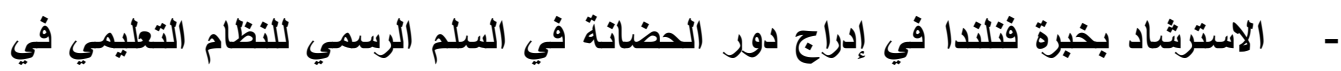
المملكة، وجعل الالتحاق بها محدودا بضوابط معينة، كأن يكون الوالدان منشغلان

$$
\text { بالعمل في الفترة الصباحية. }
$$

- الاهتمام بمرحلة رياض الأطفال، وإعداد مناهج علمية مبسطة تقوم على تطوير الطقل وتنمية مهاراته اللغوية والأكاديمية والاجتماعية، مما يخفف الحمل عن عاتق معلم الصف الأول بالمرحلة الابتدائية، مع استقبال الروضة للأطفال من سن الرابعة إلى سن

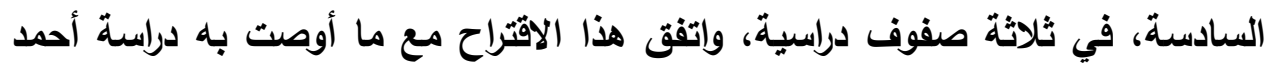

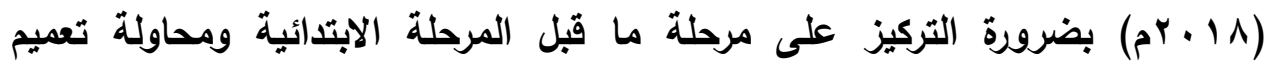
مؤسساتها واعتبارها مرحلة تعليمية ضمن مراحل سلم التعليم العام. - الاسترشاد بخبرة اليابان في ضم رياض الأطفال ضمن السلم التعليمي الرسمي. تعديل الشكل الظاهري للسلم التعليمي ૧-r-r إلى الابتدائية: ستة أعوام كما هي. المتوسطة: سنتان، تعد هذه المرحلة حساسة لانتقال الطلاب من مرحلة الطفولة إلى مرحلة المراهقة، فيقترح أن تكون هذه المرحلة مكثفة على إعداد الطلاب. لمان. الثانوية: تكون ضمن شقين، السنتان الأولى منها تسمى بالثانوية العامة ويقدم فيها برامج أكاديمية وأخرى حرفية عامة، مع التركيز على الإمكانات والتقتيات الحديثة في التعليم حتى بنى يستطيع الطلاب خلال هذه المرحلة من معرفة ميولهم. الثق الثاني: يقترح أن تسمى السنتان المتبقية بالثانوية المتخصصة، فمن هن خلال المرحلة العامة قد استطاع الطلاب تحديد ميولهم واهتماماتهم، ويتم في هذه المرحلة تكثيف الجانب

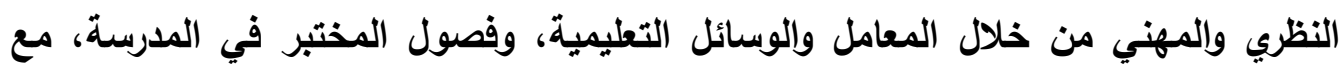


انتهاء هذه المرحلة باختبار يحدد مدى إتقان الطالب في التخصص المختار ومن ثم تأهيله

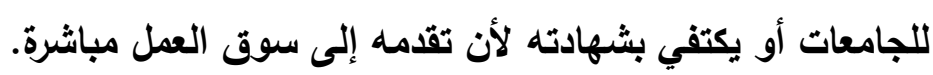

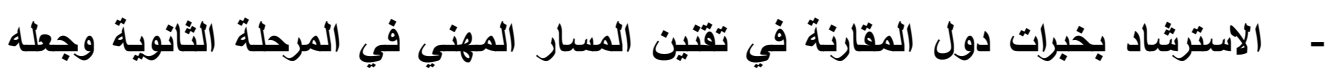

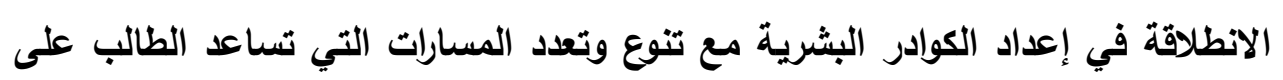

$$
\text { اختيار ما يلائم ميوله. }
$$

- الاسترشاد بخبرة دولة الإمارات في التخلي عن مساري الأدبي والعلمي في المرحلة الثانوية، وإعادة النظر في مسارات المرحلة الثانوية في المملكة العربية السعودية.

النتائج:

ركزت دولة فنلندا مرحلة ما قبل الابتدائي بشكل كبير وعلى الجانب المهني ما بعد

$$
\text { المرحلة المتوسطة. }
$$

دولة الإمارات العربية المتحدة تفردت بسلم تعليمي مختلف، واستحدثت مسارات جديدة

$$
\text { للتعليم الثانوي. }
$$

تعددت أنماط المرحلة الثانوية في اليابان.

دولة الامارات العربية المتحدة واليابان السنة الدراسة تمتد لثلاثة فصول اليانة دراسية.

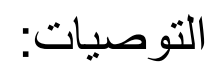

إجراء الدراسات والبحوث، وعقد المؤتمرات المحلية والدولية حول تطوير السلم التعليمي

في المملكة العربية السعودية.

• توظيف اقتصاد المملكة في إجراء الخطط والتعديلات اللازمة للسلم التعليمي من قبل وكالة التخطيط والتطوير والجهات المختصة.

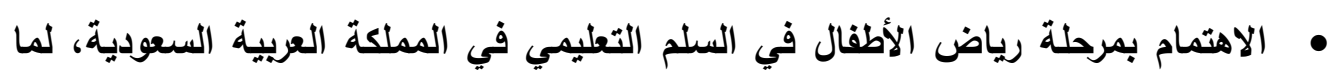
لهذه المرحلة من أهمية في تكوين القيم والاتجاهات، في نفس الطقل ويالأساليب المناسبة لهذه المرحلة العمرية كأول درجة في السلم التعليمي. 


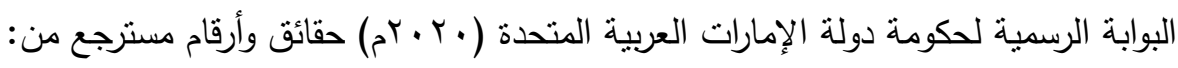
https://2u.pw/DWHkF

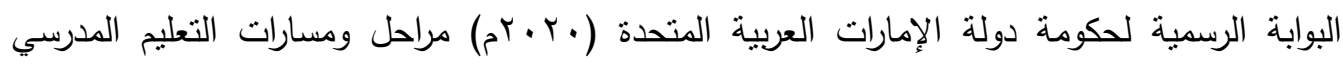
https://2U.pw/n2SBT مسترجع من

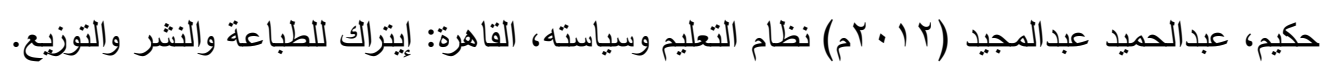

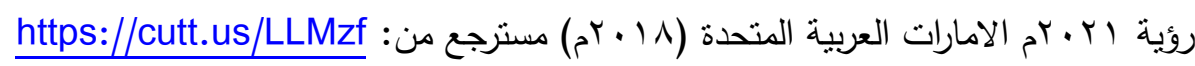

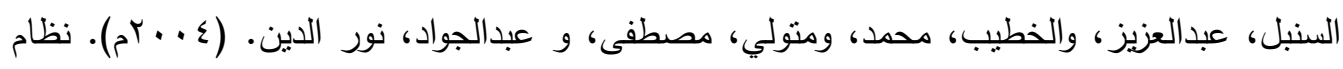

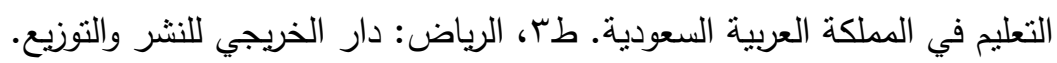

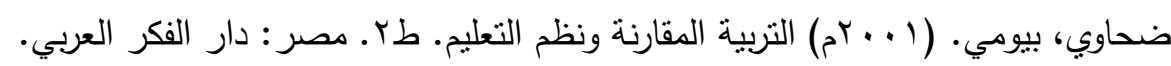

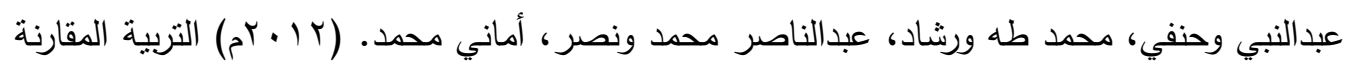
ونظم التعليم. الرياض: مكتبة الرشد.

عبود، عبدالغني وضحاوي، بيومي وسلامة، عادل عبدالفتاح وبكر ، عبدالجواد السيد. (1 (. . بم) التربية المقارنة والألفية الثالثة الايدلوجيا والتربية والنظام العالمي الجديد. مصر : دار الفكري العربي. غنايم، مهني. (9 ( • rم) التربية المقارنة ونظم التعليم. القاهرة: دار الفكر العربي.

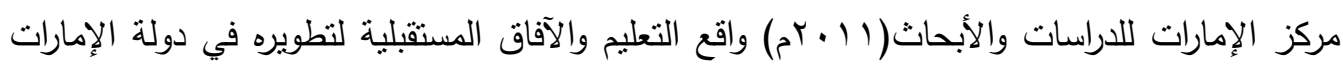

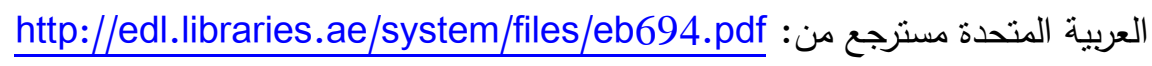
مصطفى، صلاح عبدالحميد. (ع ا •rم) المدخل في التربية المقارنة ونظم التعليم. الرياض: مكتبة الرشند.

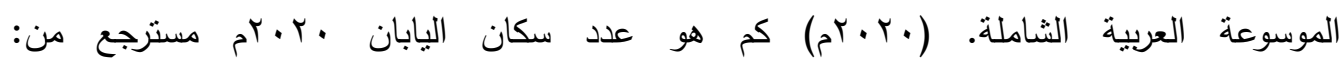
https:/www.mosoah.com/references/ask-an-experts/what-is-the/population-of-japan

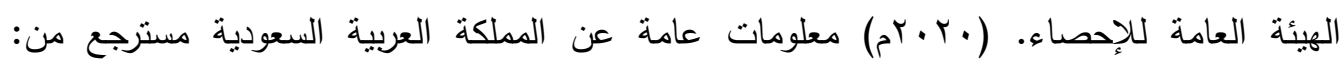
https://www.stats.gov.sa/ar/4025

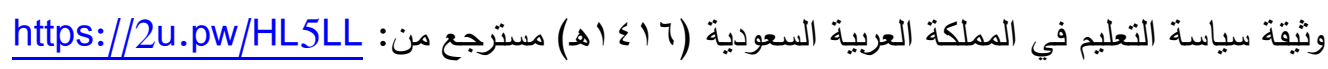

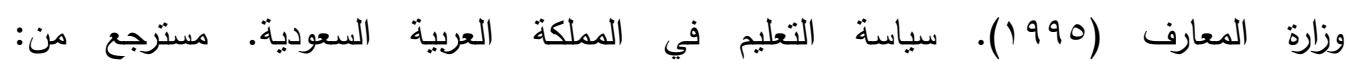
https://www.almekbel.net/PolicyofKsa.pdf 


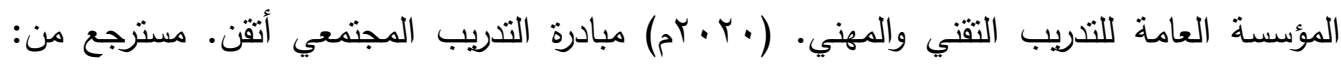
https://ctc.tvtc.gov.sa/\#/home/faq

أحمد، أحمد محمد. (1 (•rم). الاتجاهات الحديثة في تطويرا لسلم التعليمي: دراسة تحليلية، المجلة

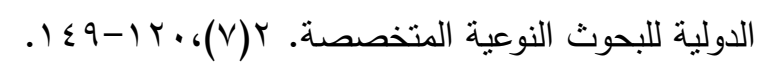

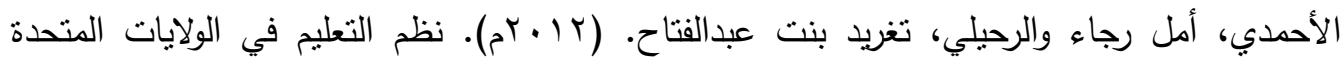

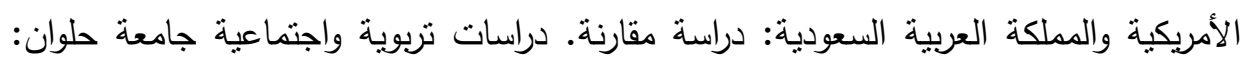

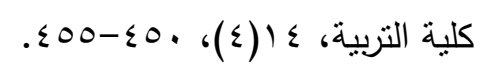

الأحمدي، فؤاد لافي مسفر • (1 ( ب (ب). نظام التعليم في فنلندا والإمارات العربية المتحدة: دراسة مقارنة

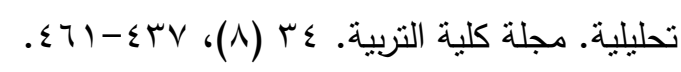

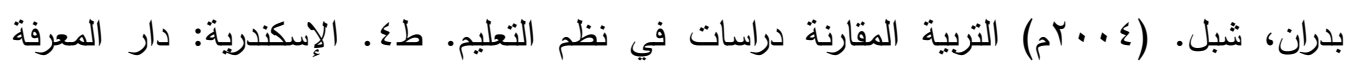
الجامعية.

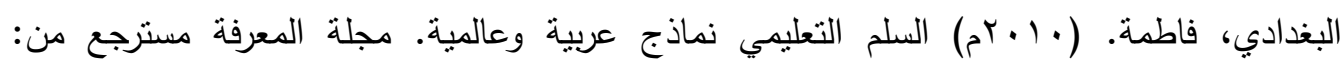
http://www.almarefh.net/show_content_sub.php?CUV=377\&Model=M\&S ubModel=160\&ID=825\&ShowAll=On بكر، عبدالجواد السيد. (1 ا • rم). إصلاح النظام التعليمي الإلزامي في فنلندا وكيفية الإفادة منه في

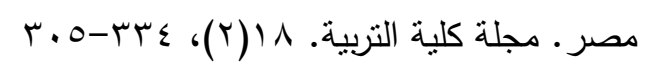

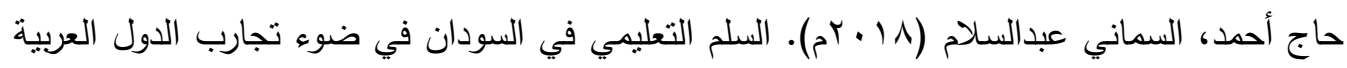

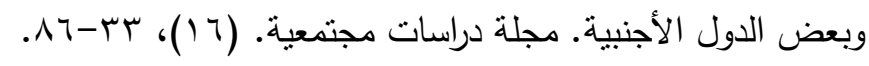

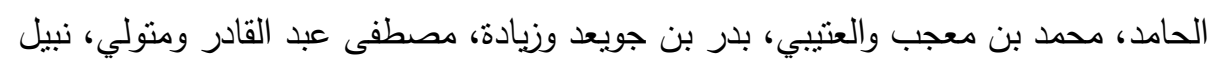
عبدالخالق.(V . • rم). التعليم في المملكة العربية السعودية رؤية الحاضر واستشراف المستقبل. (طع). الرياض: مكتبة الرشد ناشرون.

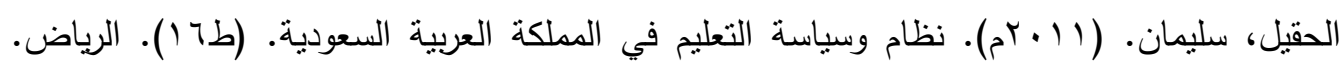
مكتبة الملك فهد.

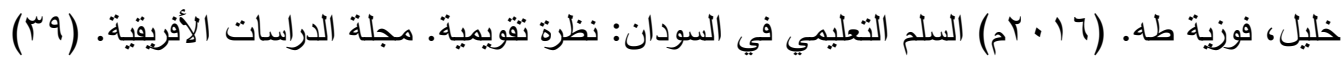

$$
r \wedge \Lambda-r \leqslant 0
$$

الخياط، نوال (r..rم). الملك خالد بن عبدالعزيز آل سعود دراسة تاريخية وحضارية (رسالة من: ماجستير ).مسترجع 
http://www.kingkhalid.org.sa/Gallery/Text/ViewBooks.aspx?view=tree\&B

$$
\text { ookID=7\&cntrlld=1\#1 }
$$

الدخيل، عزام، (10 • rم)، تعلو معهم: نظرة في تعليم الدول العشر الأوائل في مجال التعليم عبر

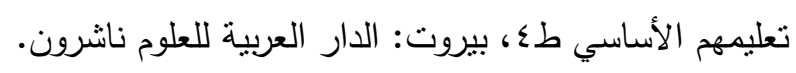

السنبل، عبدالعزيز بن عبداله والخطيب، محمد شحات ومتولي، مصطفى محمد وعبدالجواد، نور الدين.

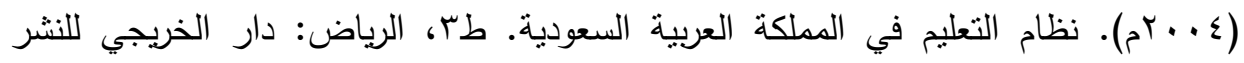
والتوزيع.

العامري، محمد عمر علي. (V V • rم). مدخل إلى التربية المقارنة. الأردن: دار المعتز للنشر والتوزيع.

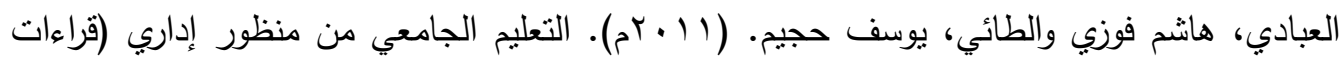

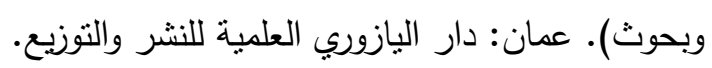

عبد الأحد، ظهير أحمد (1) • بح). تطور نظام التعليم في جمهورية الهند والعوامل المؤثرة فيه. مجلة

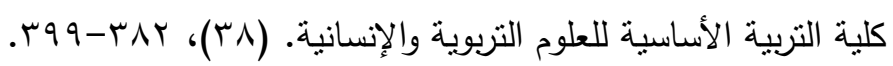

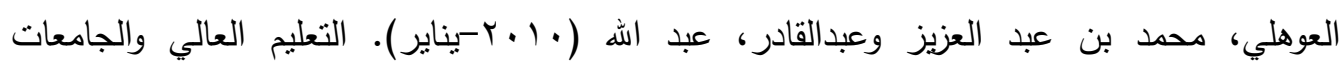

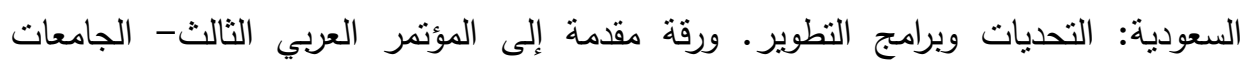

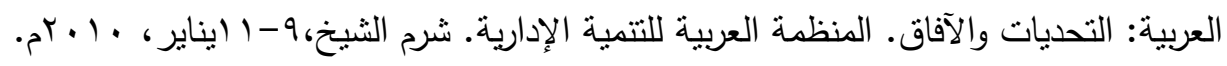

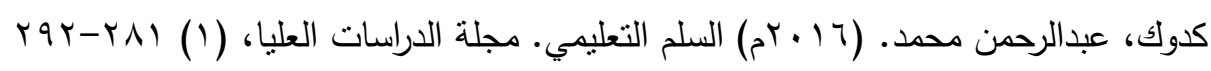

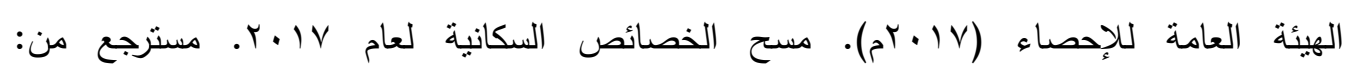
https://www.stats.gov.sa/sites/default/files/population_characteristic البوابة الرسمية لحكومة دولة الامارات العربية المتحدة. (•r.r.r). التعليم الجيد. مسترجع من: https://u.ae/ar-ae/about-the-uae/leaving-no-onebehind/4qualityeducation الكويت، وزارة التربية. (1919م). نشأة السم التعليمي وتطوره في دولة الكويت. ندوة نوحيد السلم

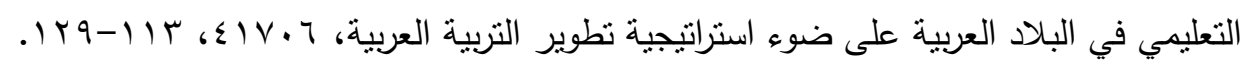

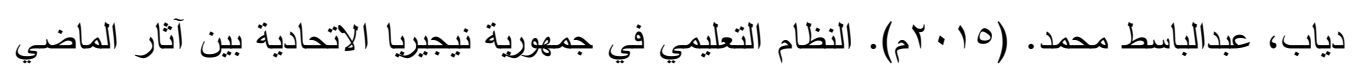

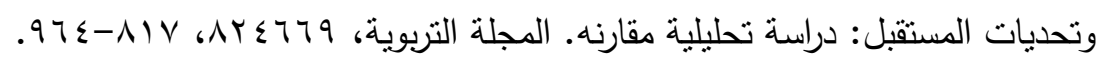

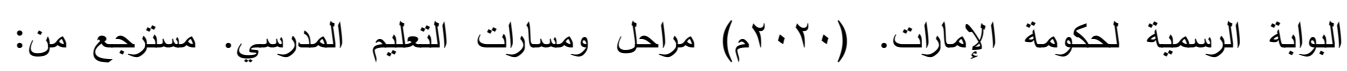
https://u.ae/ar-ae/information-and-services/education/school- 
education-k-12/joining-k-12-education/stages-and-streams-ofschool-education

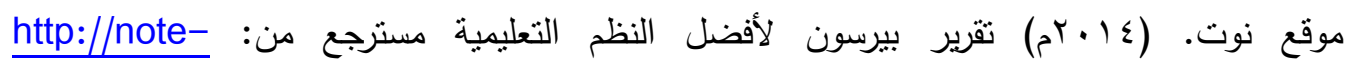
mag.com/archives/2476

البابطين، أماني أحمد. (19 •rr) تتويع مصادر نظام تمويل التعليم في المملكة العربية السعودية

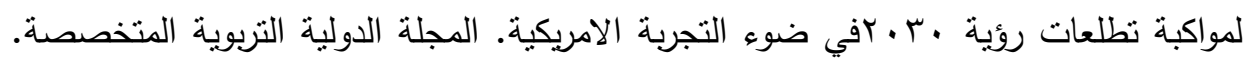
$.79-00(9) \wedge$

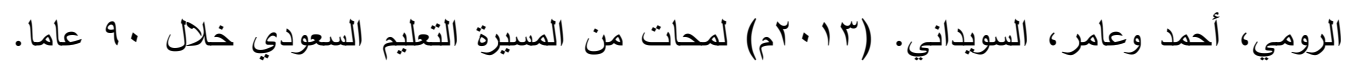

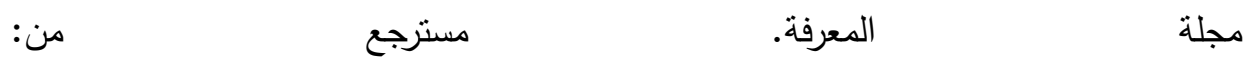

http://www.almarefh.net/show_content_sub.php?SubModel=\&ID=2063

مجلس الامة. (·.Y.Y. التعليم الحكومي في الكويت مشكلاته وسبل الحل. مسترجع من: http://www.kna.kw/clt-html5/run.asp?id=1414

مكتب التربية العربية لدول الخليج. (•r.r.r) التعليم والتثريب في سلطنة عمان. مسترجع من: https://www.abegs.org/displaysystems/6263255781605376

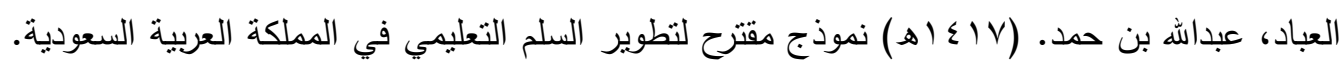

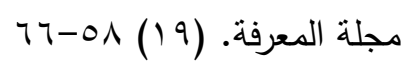

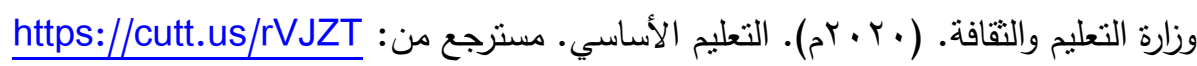

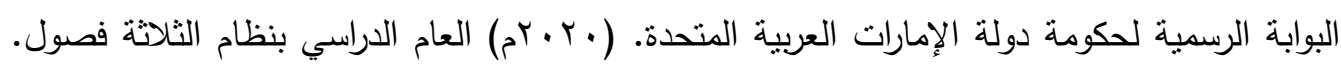
https://2u.pw/Rx9dC بنرجع من 